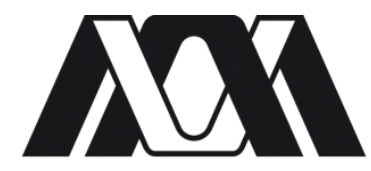

cansentastitumo

UNIVERSIDAD AUTÓNOMA METROPOLITANA

Unidad Iztapalapa

División de Ciencias Sociales y Humanidades

Departamento de Filosofía

Posgrado en Humanidades

\title{
La comprensión lingüística y el seguimiento de reglas en el segundo Wittgenstein
}

\author{
Idónea Comunicación de Resultados que \\ para obtener el grado de Maestro en Humanidades, \\ Línea de Filosofía de las Ciencias y del Lenguaje presenta:
}

Miguel Ángel Barrueta Alcaráz

Matrícula:

2143801274

Asesor:

José Jorge Max Fernández de Castro Tapia

Ciudad de México, enero de 2018 
LA COMPRENSIÓN LINGÜISTICA Y EL SEGUIMIENTO DE REGLAS EN EL SEGUNDO WITTGENSTEIN
En la Ciudad de México, se presentaron a las 8:00 horas del día 5 del mes de julio del año 2018 en la Unidad Iztapalapa de la Universidad Autónoma Metropolitana, los suscritos miembros del jurado:

DR. JOSE JORGE MAX FERNANDEZ DE CASTRO TAPIA

DR. VICTOR CANTERO FLORES

DR. SILVIO JOSE MOTA PINTO
Bajo la Presidencia del primero y con carácter de Secretario el último, se reunieron para proceder al Examen de Grado cuya denominación aparece al margen, para la obtención del grado de:

MAESTRO EN HUMANIDADES (FILOSOFIA)

DE: MIGUEL ANGEL BARRUETA ALCARAZ

y de acuerdo con el artículo 78 fracción III del Reglamento de Estudios Superiores de la Universidad Autónoma Metropolitana, los miembros del jurado resolvieron:

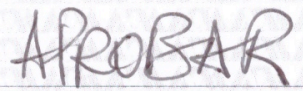

Acto continuo, el presidente del jurado comunicó al interesado el resultado de la evaluación $y$, en caso aprobatorio, le fue tomada la protesta.
LIC. JULIO CESARI OE LARA ISASSI

DIRECTOR DE SISTEMIAS ESCOLARES

iNGUELANGEL BARRUETAALCARAZ

ALUMNO

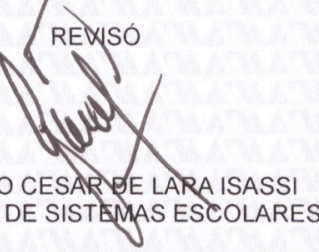

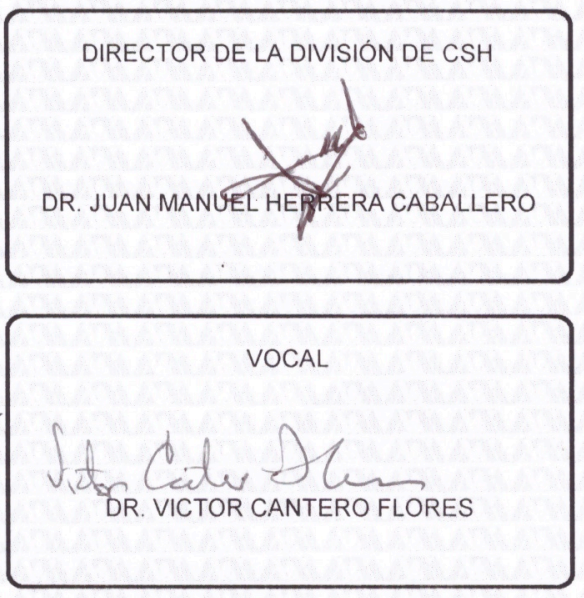

PRESIDENTE

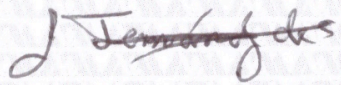

DR. JOSE JORGE MAX FERNANDEZ DE CASTRO TAPIA

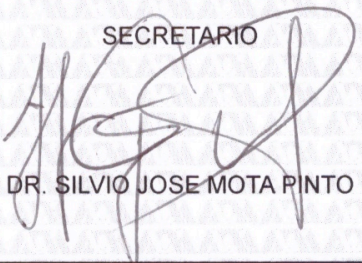


Introducción: La comprensión lingüística y el seguimiento de reglas en el segundo Wittgenstein

1 Wittgenstein vs Tractatus Logico Philosophicus 9

1.1 Los nombres como etiquetas: La visión tractariana del lenguaje

1.2 Definiciones ostensivas

1.3 Posibles objeciones: Ostensiones como actos internos

1.4 Los objetos (simples) y la determinación del sentido en el Tractatus LogicoPhilosophicus

2 Antirrealismo: Kripke y el argumento escéptico sobre el seguir una regla

2.1 La paradoja Wittgenstein/Kripke

2.2 Posibles soluciones para el reto escéptico

3 Comprensión lingüística y realismo. McGinn: Críticas a la paradoja escéptica y solución comunitarista

3.1 Esbozo y crítica de la solución escéptica (Kripke)

3.2 La estrategia realista de McGinn vs el antirrealismo de Kripke

3.2.1 El argumento escéptico y la extensión a las categorías semánticas

3.2.2 El argumento escéptico y la noción de referir

3.2.3 El argumento escéptico y la extensión a la noción de conceptos

4 Solución al reto escéptico

Conclusiones

90

Bibliografía 


\section{Introducción}

\section{La comprensión lingüística y el seguimiento de reglas en el segundo Wittgenstein}

A primera vista el nombre de esta tesis parece no tener gran relación. Podríamos pensar que la comprensión lingüística tal como el hombre de la calle la entiende es, sin mayor problema, algo que surge de manera espontánea cuando adquirimos cierta edad y con ella la capacidad de reconocer, discriminar, identificar, clasificar, ciertas palabras — de ahí en adelante nuestro arsenal de palabras va en aumento-. Sin embargo, el uso y el manejo de palabras implica formar parte de una comunidad que usa, sigue y profiere ítems del lenguaje de manera que podríamos Ilamar convencional; es decir, tener la capacidad de responder, preguntar, ordenar significa tener la destreza de utilizar el lenguaje en diversas maneras. No obstante, para poder ostentar el título de hablante competente de algún idioma, es preciso adquirir cierta destreza en cuanto a la comunicación con los demás miembros de la comunidad. Es por dicha comunidad que aprendemos el significado y el uso que debe hacerse de las palabras. La oración anterior, como puede verse, resalta la palabra 'debe', ya que parte fundamental de lo que se discutirá más adelante es que el significado que asociamos con las palabras conlleva una carga normativa. A grandes rasgos tener la capacidad de utilizar palabras de manera correcta implica, como diría Wittgenstein, seguir una regla.

La mayoría de nosotros, en estados normales de conciencia, sabemos cuándo una palabra es aplicada correctamente y cuándo no. En otras palabras, la normatividad viene 
asociada a las reglas de modo en cómo hablamos y por qué lo hacemos de ese modo y no de otro.

Normalmente asociamos una manera correcta y una incorrecta de expresarnos. He ahí donde surge la relación entre la comprensión y el seguir una regla, i.e., dominar un lenguaje significa seguir ciertas reglas que rigen la comunicación y cuando ésta es exitosa parece dar cuenta de que los criterios que dictan la corrección han sido seguidos por los participantes. En caso de que alguno de los miembros falle, ya sea intencionalmente o no, la comunicación se verá mermada. Esto no quiere decir que la comunicación falle por completo; hay casos donde aparecen malapropismos ${ }^{1}$ y parece que la conversación, a pesar del repentino sesgo, sigue su curso sin mayor problema.

Von Wright en su libro Norm and Action ha hecho ya algunas observaciones para distinguir la noción de 'normatividad' y con ello las de normas que atañen de manera explícita al 'significado'. Él piensa que parte fundamental para hacer dicha distinción radica en aquel contraste entre prescriptivo y descriptivo. Por ejemplo, tenemos que las leyes de la naturaleza son descriptivas y no prescriptivas; por lo tanto, éstas no pueden sustentar el título de normas. Por otro lado, tenemos las leyes del estado cuya función es prescribir la conducta y la interacción humana; es decir, éstas normas que fungen como juicios de valor, no tienen valor de verdad en el sentido de que no son descriptivas. El objetivo principal de estas normas regulativas es influenciar y encaminar la conducta humana del mejor modo posible. Sin embargo, hemos de ser más precisos al intentar definir dichas nociones.

\footnotetext{
${ }^{1}$ Por malapropismo debe entenderse la sustitución de una palabra con sonido semejante por otra con significado totalmente distinto.
} 
Consideremos el significado de 'ley' en la expresión 'leyes de la lógica'. En lógica, hay, por lo menos dos principios. La ley del tercer excluso y la ley de no contradicción. En el primer caso la enunciamos del siguiente modo: cada proposición o bien es verdadera o bien es falsa. El segundo principio dice: ninguna proposición es verdadera y falsa. Entonces, surge la pregunta ¿son dichas leyes descriptivas o prescriptivas? Si las tomamos como descriptivas, entonces debemos de ser capaces de decir qué es lo que describen. ¿Describen la manera en que la gente piensa ${ }^{2}$ Visto de este modo sería difícil reconciliar, por un lado, la idea de que las leyes de la lógica describen cómo piensa la gente y por otro lado el carácter a priori y, por lo tanto, su independencia de la experiencia. Veamos la segunda opción. Supongamos que dado el carácter a priori de dichas leyes, nos resulta de mayor plausibilidad situarlas en el ámbito prescriptivo. Diríamos, entonces, que las leyes de la lógica son aquellas que prescriben de qué manera debemos pensar y de qué manera no. Sin embargo, si respondemos afirmativamente la pregunta, podemos ver que hay una diferencia entre el modo en que las leyes de la lógica permiten, prohíben, permiten, etc., y el modo en que lo hacen las leyes del estado. Dicho así, podemos diferenciar entre las distintas formas que tienen las leyes de prescribir. Es decir, las leyes de la lógica prescriben de un modo diferente a como lo hacen las leyes del estado. Por su parte, las leyes de la lógica prescriben cómo y de qué manera debería uno pensar para que los razonamientos obtenidos sean correctos. Es decir, las leyes de la lógica son aquellos vehículos que dictan las reglas para que los argumentos puedan ser caracterizados como válidos. Sin embargo, dichas reglas no obligan, por lo menos de manera coercitiva, a actuar conforme a lo que

\footnotetext{
${ }^{2}$ Quizá podríamos decir que describen parte del espacio modal, es decir, qué es possible y qué no.
} 
estipulan, mientras que las leyes del estado, al ser violadas, en la mayoría de los casos conlleva una sanción punitiva. Tanto las leyes del estado como las leyes de la lógica tienen la facultad de prescribir, no obstante, hay diferencias sutiles en el modo en que lo hacen. Es decir, las leyes de la lógica nos ofrecen un estándar para juzgar si la gente piensa de manera correcta o no. Las leyes del estado tienen consecuencias jurídicas en el caso de ser transgredidas. Dichas aclaraciones sirven para mostrar que si bien las leyes pertenecen a dicha categoría es porque ambas prescriben, aunque, como ya se ha aclarado, el modo en que lo hacen es totalmente distinto.

Nos dice von Wright:

Sin embargo, decir que las leyes de la lógica prescriben de qué manera debe pensar la gente si lo quiere hacer correctamente es un modo peligroso y desafiante de hablar. Sugiere que las funciones 'prescriptivas' de las leyes de la lógica tienen un lugar secundario a las funciones 'descriptivas' como indicadores de los principios del razonamiento correcto. En primer lugar, las leyes de la lógica y de las matemáticas establecen verdades sobre entidades lógicas y matemáticas -proposiciones, relaciones, inferencias, números, etc. Esto lo hacen de manera explícita cuando se formulan de manera usual, por ejemplo, cuando decimos, 'Cada proposición o bien es verdadera o bien es falsa'. Por lo tanto, el punto de vista de que las leyes de la lógica son prescriptivas sugieren que dichas leyes, en primer lugar, son descriptivas. ${ }^{3}$

\footnotetext{
3 "Yet to say that the laws of logic prescribe how people have to think in order to think correctly is a challenging and dangerous way of talking. It suggests that 'prescriptive' functions of the laws of logic is secondary to a 'descriptive' function of them as stating principles of correct thinking. Primarily, the laws of logic and
} 
Creo yo que lo que muestra la cita antes mencionada es que las leyes de la lógica no describen cómo piensa la gente, sino cómo están constituidas las entidades de la lógica. La cuestión que nos interesa es la siguiente: ¿son las leyes de la matemática descriptivas o prescriptivas? Es decir, las leyes de la lógica nos muestran cómo deberíamos pensar y/o nos dicen cómo están constituidas aquellas entidades lógicas. Desde mi punto de vista, la diferencia puede verse de mejor manera si dichas leyes se comparan con las reglas de un juego. Es decir, jugar un juego es una actividad al igual que lo que hacemos cuando calculamos, inferimos, en lógica. Si comparamos la lógica con un juego de ajedrez podemos ver que en esencia son muy similares, en tanto que ambos tienen reglas específicas que dictan los cursos de acción a seguir. Por su parte, las reglas establecidas del ajedrez nos dictan cuáles piezas y de qué forma han de moverse. Y, por otro lado, en lógica, las reglas nos permiten determinar qué inferencias, afirmaciones son correctas en el ámbito del pensamiento. Por ejemplo, supongamos que un jugador de ajedrez no sigue las reglas; en este caso diríamos que no juega de manera correcta o que quizá juega algún otro juego. De manera análoga, podríamos pensar lo mismo de alguien que resuelve acertijos lógicos de manera errónea. Es decir, si tal persona no da la respuesta adecuada según la inferencia correcta, entonces diríamos que la persona en cuestión no sigue las reglas inferenciales o, sigue otras reglas o, que no hace las inferencias. Sin embargo, hay que notar, como apunta

mathematics state truth about the logical and mathematical entities -propositions, relations, inferences, numbers, etc. This they also do overtly when formulated in the usual way, as, e.g., when we say, 'Every proposition is either true or false'. Thus the view of the laws of the logic as prescriptive of the way people ought to think leads to a view of these laws as being, primarily, descriptive". (1963) 
Von Wright, que la noción de jugar de manera errada ya sea por desconocimiento de las reglas, ya sea por intenciones fraudulentas, sólo se encuentra en discordancia con las reglas del juego mismo. Por otro lado, aquel sujeto que contraviene las leyes de la lógica se encuentra en oposición a la racionalidad. La diferencia radica, por lo tanto, en que las reglas del juego son convencionales, por decirlo de algún modo creaciones humanas, y estas pueden ser modificadas, añadidas o cambiadas a plena voluntad de los jugadores. Sin embargo, las leyes de la lógica no son convencionales en el sentido de que pueden ser cambiadas a voluntad propia.

Al parecer no hemos hallado una caracterización sobre si las leyes de la lógica son prescriptivas o, bien, descriptivas. A saber, hemos visto que no son descriptivas en comparación con las leyes de la naturaleza y tampoco hemos podido concederles la categoría de prescriptivas en el sentido de las leyes que rigen el estado ${ }^{4}$.

Sigue von Wright:

[...] la comparación de las leyes de la lógica (matemáticas) con los juegos sugiere una nueva caracterización de dichas leyes. De acuerdo con esta nueva caracterización, las leyes de la lógica (matemáticas) no describen ni prescriben, pero determinan algo. Independientemente de lo que pensemos sobre la comparación, podemos estar de acuerdo con la utilidad de tal caracterización. ${ }^{5}$

\footnotetext{
${ }^{4}$ Los ejemplos antes mencionados sirven para dar cuenta de la ambigüedad de la palabra "ley" y mostrar a grandes rasgos las diferencias entre prescriptivo y descriptivo.

5 "...the comparison of the laws of logic (mathematics) to the rules of a game suggested a new characterization of these laws. According to this new characterization, the laws of logic (mathematics) neither describe nor prescribe, but determine something. Irrespective of what we think of the comparison in other respects, we can agree to the usefulness of this characterization." (1963)
} 
Lo que me parece que nos quiere decir von Wright es que el término 'ley' es ambiguo y puede entenderse de maneras distintas. Es decir, qué tipo de normatividad es posible atribuir a las leyes de la lógica.

En el primer capítulo se expondrán los preliminares con respecto a la filosofía del primer Wittgenstein y el cambio radical que muestra en su segundo periodo. Es decir, pretendo mostrar que la filosofía de lo que suele llamarse el primer Wittgenstein tiene tintes descriptivos, mientras que en las Investigaciones se adopta un corte de tipo prescriptivo. Es decir, sostengo que el hecho de ser descriptivista, sería explicar el significado en virtud de sus condiciones de verdad. Y, por el contrario, ser prescriptivista requiere explicar el significado a través de las condiciones de aseverabilidad.

Los capítulos siguientes pretenden mostrar dos corrientes antagónicas que han sido de particular interés con respecto a la comprensión lingüística. En especial, el segundo de ellos estará destinado a la exposición de Kripke y la paradoja que subyace al problema de seguir una regla, el antirrealismo. El tercer capítulo será dedicado a Collin McGinn y su realismo con respecto a la comprensión. A lo largo de la tesis debe entenderse que la disputa entre realismo y antirrealismo se basa en que los primeros defienden que hay hechos sobre la comprensión lingüística - es decir, existe la convicción de que captar el significado de una palabra conlleva la existencia de un hecho 6 -, mientras que los segundos niegan que existan hechos sobre la comprensión lingüística.

\footnotetext{
${ }^{6}$ En el sentido de que, regularmente, pensamos que querer decir algo mediante un signo depende en gran medida de algunos aspectos y/o eventos que ocurren en su mente.
} 
La postura que defiendo a lo largo de la tesis es la de Kripke con respecto al lenguaje y, por lo tanto, la antirrealista. La conclusión que se obtiene a partir del análisis es que nuestra noción de que un sujeto quiera decir algo mediante un signo es factualmente vacía, ${ }^{7}$ esto es, que no hay ningún hecho que constituya que un sujeto quiera decir algo con un signo. En otras palabras, los significados no son estados internos, más bien, la postura defendida por Kripke es que los significados se conforman por las reglas y convenciones establecidas a través de una comunidad lingüística. Los significados se constituyen a partir de una comunidad que usa las palabras de cierta manera y se obtiene certeza de que son usadas de manera correcta, ya que son los mismos miembros de la comunidad los que ratifican que así sea.

Por otro lado, creo que la exposición que hace Kripke de Wittgenstein muestra que el problema de seguir una regla es un argumento por sí mismo relevante y sofisticado. Algunos han dicho - entre ellos McGinn- que la paradoja no es algo que haya querido refrendar strictu sensu Wittgenstein. Sin embargo, a mi parecer Kripke expone de manera más clara e inteligible los parágrafos concebidos como el problema de seguir una regla. Si el argumento de Kripke tiene relevancia e influencia en áreas como la filosofía de la mente, del lenguaje, metafísica, etc., pienso que habría que considerarlo de suma importancia por sí mismo, y no partiendo de si es o no una fiel exégesis de Wittgenstein.

7 No son enunciados semánticamente declarativos. 


\section{1}

\section{Wittgenstein vs Tractatus Logico Philosophicus}

Como es bien sabido, Wittgenstein consideró que sería buena idea poner en conjunto sus pensamientos vertidos en su primera obra con los de su segundo periodo, i.e., las Investigaciones Filosóficas. Así, el mismo apunta:

Hace cuatro años tuve ocasión de volver a leer mi primer libro (el Tractatus LogicoPhilosophicus) y de explicar sus pensamientos. Entonces me pareció de repente que debía publicar juntos esos viejos pensamientos y los nuevos; que éstos sólo podían recibir su correcta iluminación con el contraste y en el trasfondo de mi viejo modo de pensar. ${ }^{8}$

Quizás este sea, sin duda, uno de los prefacios mejor conocidos y citados que cualquier otro sobre filosofía. La importancia de dicho prefacio reside en el trabajo efectuado por Wittgenstein y en sus críticas hacia su primera obra. En este primer capítulo intento mostrar el distanciamiento de lo que suele llamarse el primer y segundo Wittgenstein, es decir,

\footnotetext{
8 "Four years ago I had occasion to re-read my first book (the Tractatus Logico - Philosophicus) and to explain its ideas to someone. It suddenly seemed to me that I should publish those old thoughts and the new ones together: that the latter could be seen in the right light only in contrast with and against the background of my old way of thinking" (Las traducciones de las Investigaciones Filosóficas fueran tomadas de la versión en español: Wittgenstein, Ludwig (2004), Investigaciones Filosóficas, Barcelona, UNAM/Crítica).
} 
sostengo que entender el problema de seguir una regla requiere entender algunas nociones que aparecen en el primer periodo. Por lo menos, creo yo, los primeros 137 parágrafos de las Investigaciones son destinados a una crítica de nociones centrales que aparecen en el Tractatus con alusiones al lenguaje, referencia, nombres, reglas, etc. Es decir, el problema de las reglas aparece desde antes de las Investigaciones, a saber, en las definiciones ostensivas. ¿Cómo aprendemos lo que significa una definición ostensiva? Al parecer, la respuesta es que hay una regla, un modo de adiestramiento que nos dicta cómo han de entenderse. Esto es, entender una definición ostensiva es captar una regla. Sin embargo, la posibilidad de malinterpretar dichas definiciones es lo que da cabida al reto escéptico.

Una de las primeras críticas con respecto al lenguaje que aparece en el Tractatus se da a inicios de sus Investigaciones. Aquí el filósofo vienés reniega primero de lo que parece ser la esencia del lenguaje, i.e., las palabras están por objetos, mientras que las oraciones son compuestos de esas palabras que figuran cómo están los objetos en el mundo. En particular, me parece que la cita de Agustín que abre paso a las Investigaciones da muestra precisa de los errores que se encuentran en su obra temprana:

Cuando ellos (los mayores) nombraban alguna cosa y consecuentemente con esa apelación se movían hacia algo, lo veía y comprendía que con los sonidos que pronunciaban Ilamaban ellos a aquella cosa cuando pretendían señalarla. Pues lo que ellos pretendían se entresacaba de su movimiento corporal: cual lenguaje natural de todos los pueblos que con mímica y juegos de ojos, con el movimiento del resto de los miembros y con el sonido de la voz hacen indicación de las afecciones del alma al apetecer, tener, rechazar, o evitar cosas. Así, oyendo repetidamente las palabras colocadas en sus lugares apropiados en 
diferentes oraciones, colegía paulatinamente de qué cosas eran signos, y una vez adiestrada la lengua en esos signos, expresaba ya con ellos mis deseos. ${ }^{9}$

Lo que muestra la cita de Agustín es una imagen particular que hace alusión a la visión tractariana del lenguaje, es decir, muestra una manera incompleta de explicar el lenguaje. ${ }^{10}$ Al parecer tenemos, según el inicio de las Investigaciones, afirmaciones controversiales en torno a cómo y de qué manera funciona el lenguaje. Partimos de que al equiparar el texto de Agustín con las Investigaciones notamos que puede no ser adecuado a cómo expuso sus ideas anteriores. Es decir, ¿por qué hemos de tomar como importantes aquellas observaciones que refutan el Tractatus?, ya que podría pensarse que la cita de Agustín muestra afirmaciones que no cualquiera podría o quisiera sostener. Existe por lo menos una razón por la que se cree que Wittgenstein inicia en el modo en que lo hace. Como sabemos, nunca tuvo una manera ortodoxa de escribir filosofía; sin embargo, supongo que al echar mano de Agustín, Wittgenstein empieza por describir cómo funciona en términos generales el lenguaje, es decir, explicando la concepción agustiniana del lenguaje. Esto, por supuesto, no quiere decir que todo lo que describe dicha cita logre explicar a cabalidad la complejidad del lenguaje. En general, podríamos decir que la imagen más clara del lenguaje en el Tractatus se explicaría de la siguiente manera: la esencia del lenguaje consiste en que las

\footnotetext{
9 "When they (my elders) named some object, and accordingly moved toward something, I saw this and I grasped that the thing was called by the sound they uttered when they meant to point it out. Their intention was shewn by their bodily movements, as it were the natural language of all peoples: the expression, the play of the eyes, the movement of other parts of the body, and the tone of voice which expresses our state of mind in seeking, having, rejecting, or avoiding something. Thus, as I heard words repeatedly used in the proper places in various sentences, I gradually learnt to understand what objects they signified; and after I had trained my mouth to form these signs, I use them to express my own desires". (PI, §1)

${ }^{10}$ Es importante mencionar que, a pesar de que Wittgenstein cite a Agustín, no piensa que todas las palabras refieren a objetos, e.g., las constantes lógicas.
} 
palabras están por cosas en el mundo, dichas cosas son sus significados y las oraciones son combinaciones de dichas palabras. A pesar de que el Tractatus sea por mucho más complejo, la idea general, me parece se esboza de manera correcta. Es decir, el Tractatus funge como una teoría sofisticada que logra explicar rasgos esenciales primitivos.

\section{1}

\section{Los nombres como etiquetas: La visión tractariana del lenguaje}

Hemos visto que el inicio de las Investigaciones da una idea general del lenguaje. Sin embargo, el trabajo del filósofo vienés se perfilará justamente a criticar dichas ideas. Tenemos, por lo pronto, dos puntos de ataque. En primer lugar, notamos que los nombres no funcionan meramente como etiquetas de los objetos, es decir, vemos que cuando son utilizados en el lenguaje se comportan de maneras distintas. La crítica intenta mostrar que no todas las palabras funcionan como nombres. En ocasiones se utilizan para describir, contar y/o enumerar. Wittgenstein crea un juego en función de mostrar que los nombres son utilizados de distintas formas. A una persona le es entregada una nota con la siguiente leyenda 'cinco manzanas rojas', a lo que ella, como ha sido entrenada, corre los números hasta el cinco y por cada uno de ellos toma una manzana y ve una muestra del color rojo en una tabla y se cerciora de que el color de la muestra sea el mismo que el de las manzanas. Esto basta para mostrar que las palabras 'cinco', 'rojo' y 'manzanas' tienen usos distintos. Mediante este tipo de juegos nos percatamos de que los usos que hacemos de las palabras 
son distintos. Por ello, nos dice: "Agustín describe, podríamos decir, un sistema de comunicación; sólo que no todo lo que llamamos lenguaje es este sistema". ${ }^{11}$

A lo largo de los primeros veinte parágrafos se dan una serie de ejemplos que incluyen demostrativos y otros tipos de palabras. Dichos ejemplos muestran la variedad de formas en las que las empleamos; por ejemplo, los deícticos los usamos en definiciones ostensivas, quizá con el objeto de enseñar el uso de otras palabras.

- Pásame eso.

- ¿El qué?

- Eso que está allí.

- ¿Aquí?

- Sí, justo ahí.

Como podemos observar, dicha conversación carece de contenido semántico si no tenemos a la mano los aspectos contextuales para saber de qué hablamos y dónde se encuentra dicho objeto. La pregunta sería la siguiente ¿cómo podría uno enseñar el uso de los deícticos? Uno podría apuntar a cosas y a objetos. Sin embargo, ahí estaríamos enseñando a usar deícticos en tal o cual caso particular, por lo cual no estaríamos explicando su significado, sino cómo se aplica en ese caso. La cuestión importante con los deícticos es que

\footnotetext{
11"Augustine, we might say, describes a system of communication; only not everything that we call language
} is this system..." (PI, §3) 
ellos toman su significado en su aplicación de casos particulares. Es decir, no se pueden explicar los usos de 'allá', 'aquí', 'eso' de manera general.

El problema, como podemos ver, es que los diferentes tipos de palabras vienen acompañados por otro tipo de cuestiones que subyacen a la gramática -al parecer el uso de las palabras regularmente lleva consigo ciertos rasgos característicos del uso-. Por ejemplo, consideremos el ánimo, las intenciones, las entonaciones e incluso la puntuación.

Recordemos la famosa comparación que hace Wittgenstein entre las palabras y las herramientas. ${ }^{12}$ Podría pensar uno en una fórmula de tipo general que explique en qué consisten las herramientas y se podría decir más o menos lo siguiente: "las herramientas sirven para modificar algo". ${ }^{13}$ En particular, estaríamos considerando herramientas del tipo que sirven para modificar como un desarmador, una segueta o un martillo. Por otro lado, ¿qué modifica, por decir algo, un clavo? Al parecer nada en particular. Aquí vemos cómo se pone de relieve el error de generalizar. No podemos decir que las palabras, así como las herramientas, tienen un sólo uso o que son de determinado tipo.

\section{2}

\section{Definiciones ostensivas}

Como hemos visto, si pensamos que aprender un lenguaje es asignar nombres a objetos, entonces podemos percatarnos de que hacemos ciertas omisiones con respecto al lenguaje. Es decir, el lenguaje visto desde este punto de vista es incompleto. En lo que sigue

\footnotetext{
${ }^{12}(\mathrm{PI}, \S 11)$

${ }^{13}(\mathrm{PI}, \S 14)$
} 
consideraremos la idea errónea de que el significado puede ser asignado a una palabra por medio de una definición ostensiva. Tomemos el siguiente ejemplo: pensemos que queremos enseñar a alguien el significado de la palabra 'dos'; para ello apuntamos a un par de nueces y decimos 'esto se llama dos'. En efecto, el aprendiz puede interpretar esto de diversas maneras. Puede suponer que nombramos ese grupo de nueces, o el tipo de nueces, o el color de las nueces o los puntos espacio-temporales donde se localizan dichas nueces. La cuestión con las definiciones ostensivas es que pueden ser interpretadas de distintos modos. Por lo tanto, podemos decir que las definiciones ostensivas al no ser precisas, no siempre pueden determinar el significado de las palabras. Es decir, siempre se puede malinterpretar una definición ostensiva, ésta puede ser interpretada por el interlocutor de manera distinta con respecto a la intención del instructor. Esto no quiere decir que algunas palabras no las aprendamos de tal modo, sólo decimos que no son una buena referencia, consideradas de manera aislada, para fijar los significados de las palabras.

Por ejemplo, la expresión 'este color es marrón' sólo puede ser comprendida si se tienen ciertas habilidades lingüísticas anteriores o si se tiene cierta familiaridad con los tonos y colores. De aquí que entender el significado de la palabra 'marrón' sea considerado como exitoso si se emplea de manera correcta. "La definición ostensiva explica el uso significado- de la palabra cuando ya está claro qué papel debe jugar en general la palabra en el lenguaje" ${ }^{14}$

Por lo tanto, no hemos de tomar las definiciones ostensivas como partes fundamentales al asignar significados a las palabras, ya que si así lo hiciéramos no

\footnotetext{
${ }^{14}(\mathrm{PI}, \S 30)$
} 
estaríamos considerando que las definiciones ostensivas requieren habilidades lingüísticas previas. En otras palabras, pensar que mediante las definiciones ostensivas se adquiere un lenguaje, significa pensar que el aprendiz ya tiene un lenguaje, es decir, se presupone el fenómeno que se estaría tratando de explicar.

Es por ello que Wittgenstein dice que nombrar y describir no están, por cierto, a un mismo nivel: nombrar es una preparación para describir. ${ }^{15}$ De este modo llegamos a la conclusión de Wittgenstein con respecto al texto de Agustín:

Agustín describe el aprendizaje del lenguaje humano como si el niño llegase a un país extraño y no entendiese el lenguaje del país; esto es: como si ya tuviese un lenguaje, sólo que no ése. O también: como si el niño ya pudiera pensar, sólo que todavía no habla. ${ }^{16}$

El punto de la explicación de la conexión lenguaje-mundo en dado en términos de definiciones ostensivas presupone que cierto lenguaje primitivo ya estuviera funcionando para el hablante de que aprende de dichas definiciones.

\footnotetext{
${ }^{15}(\mathrm{PI}, \S 49)$

16 "And now, I think, we can say: Augustine describes the learning of human language as if the child came into a strange country and did not understand the language of the country; that is, as if it already had a language, only not this one. Or again: as if the child could already think, only not yet speak". (PI, §32)
} 


\section{3}

\section{Posibles objeciones: Ostensiones como actos internos}

Como hemos visto las Investigaciones se encuentran plagadas de una dialéctica ya sea con el mismo Wittgenstein o con el sentido común mismo. En este apartado me abocaré a las críticas mismas que aparecen con respecto a las definiciones ostensivas.

Es cierto que en numerosas ocasiones intentamos explicar el significado de una palabra, usando definiciones ostensivas, con tan sólo señalar el objeto al que se hace referencia. Sin embargo, consideremos la siguiente objeción con respecto a la sección anterior:

¡No es verdad que ya tenga uno que dominar un juego del lenguaje a fin de entender una definición ostensiva, sino que sólo tiene -evidentemente- que saber (o conjeturar) a dónde señala el que explica! Si, por ejemplo, a la forma del objeto, o a su color, o al número, etc., etc. ${ }^{17}$

Como podemos observar, hay algo que puede resultar un tanto desconcertante. Es cierto que en ocasiones nos es suficiente con apuntar hacia alguna dirección en particular para saber, en sentido débil, a lo que nos referimos con dichos movimientos corporales. Sin embargo, escribo 'en sentido débil', ya que en realidad sólo estaríamos adivinando qué es lo que nos señalan. Supongamos lo siguiente: alguien señala una manzana y a su vez profiere la palabra 'rojo', podría haber ocasiones en las cuales el aprendiz no tenga ningún conocimiento previo del lenguaje, ${ }^{18}$ entonces en tal caso él podría pensar que por 'rojo' se

\footnotetext{
17 "It is not true that you must already be a master of a language in order to understand an ostensive definition: all you need -of course!- is to know or guess what the person giving the explanation is pointing to. That is, whether for example to the shape of the object, or to its colour, or to its number, and so on." (PI, §33)

${ }^{18}$ Véase la sección anterior.
} 
refiere a la forma o a la manzana misma. He ahí donde nos percataríamos de que está cometiendo un error al no saber que con la palabra 'rojo' se refería al color, no a la forma ni mucho menos al objeto mismo. La pregunta que hace Wittgenstein sería la siguiente: ¿cuál es el proceso que envuelve querer apuntar al color y no a la forma? La respuesta natural sería que justamente concentramos nuestra atención en apuntar al color. De aquí se sigue otra pregunta: ¿qué envuelve concentrar nuestra atención en el color? Es cierto que es un fenómeno que suele ser común; sin embargo, lo que se quiere atacar es que concentrar nuestra atención en ese 'algo' es un acto mental privado que regularmente llamamos señalar algo en particular. ¿Cómo señalamos la forma, cómo señalamos el color, cómo señalamos el tamaño? Quizá pensaríamos que la respuesta sería más o menos lo siguiente: diríamos que cada que hemos querido señalar hemos querido significar algo distinto. Pero, ¿no es raro? ¿de qué manera señalamos distinto?

Consideremos lo siguiente:

- ¿¿Es este azul el mismo azul de allá? ¿Ves alguna diferencia?

- Mezclas colores y dices: es difícil igualar el color del cielo.

A pesar de que en estos ejemplos nos hemos concentrado únicamente en el color, los mismos ejemplos muestran que existen diferentes fenómenos de lo que llamamos concentrarnos en el color. Supongamos, por mor del argumento, que existe un sólo tipo de características que ocurren de manera concomitante al concentrarse en el color. Si una persona intenta, por medio de una definición ostensiva, significar el color de cierto objeto lo hace de ese único modo. Ahora bien, la persona que interpreta la definición de manera 
correcta, debe haberlo hecho por un medio similar de concentrarse en dicho color. Es decir, la persona que interpreta debe captar este proceso mental de concentrarse en el color a partir de sus rasgos externos. ¿Es ésta la manera correcta de significar e interpretar ciertos rasgos fenoménicos?

Supongamos que el profesor intenta explicar mediante el uso de definiciones ostensivas el color sepia. Podría haber un aprendiz que, a pesar de estar en el mismo estado mental que el profesor, no supiera de qué manera aplicar la palabra 'sepia'. Lo que sucede es que una condición necesaria para que el aprendiz utilice de manera correcta esta palabra es que tenga la habilidad de reconocimiento y discriminación de colores. Por supuesto, el aprendiz tendrá errores mientras va adquiriendo destreza, tal que los fallos sean errores y no sean respuestas arbitrarias. Así, la interpretación de la definición ostensiva que hace el aprendiz se verá mejorada en tanto vaya aprendiendo y no se verá establecida al momento de que le fue enseñada. Es decir, las definiciones ostensivas no están determinadas por estados mentales, sino que se van aprendiendo conforme se usan en el lenguaje. La critica radica en mostrar que el intermediario mental puede estar presente sin que el aprendiz encuentre la interpretación correcta de la definición ostensiva. Por otro lado, el intermediario puede no estar presente y, sin embargo, el aprendiz interpretar la definición de manera correcta. Wittgenstein, en particular, pone especial énfasis en explicar que el significado no reside en estados mentales.

Hemos dicho que las definiciones ostensivas funcionan de manera correcta cuando hay cierto conocimiento lingüístico previo. Por lo cual, dicho conocimiento previo no pudo haber sido obtenido mediante las definiciones ostensivas. Entonces, es perfectamente 
posible preguntar ¿cómo se obtiene ese conocimiento previo? La respuesta es que las definiciones ostensivas no pueden, por sí mismas, determinar el uso de una expresión, por lo cual habría que ver qué tipo de entrenamiento es el que nos permite determinar el uso de dichas definiciones. El problema es que las ostensiones no determinan el significado de las palabras cuyo significado pretenden explicar de manera exhaustiva. No obstante, la respuesta se encuentra en la misma pregunta, ya que no hay mejor modo de aprender el uso de las definiciones más que por el propio entrenamiento. Esto es, el uso es lo que hace que se aprenda el significado de cada una de las palabras que las definiciones tienen la misión de explicar echando mano de su contexto de tiempo y lugar.

La idea de que el significado de los términos puede ser explicado a través de las elucidaciones que empleamos se remonta a la época del Tractatus Logico-Philosophicus:

Los significados de los signos primitivos pueden ser explicados mediante aclaraciones. Aclaraciones son proposiciones que contienen signos primitivos. Sólo pueden ser, pues, comprendidas si los significados de estos signos son ya conocidos. $^{19}$

A primera vista dicho parágrafo puede resultar confuso, pues parece haber un círculo vicioso. Sin embargo, éste sólo es aparente; el significado de los términos primitivos ${ }^{20}$ ha

\footnotetext{
19 "The meanings of primitive signs can be explained by means of elucidations. Elucidations are propositions that contain the primitive signs. So they can only be understood if the meanings of those signs are already known". (TLP 3.263) (Las traducciones del Tractatus Logico-Philosophicus al español refieren a la siguiente versión: Wittgenstein, Ludwig, 2002, Tractatus Logico-Philosophicus, trad. de Jacobo Muñoz e Isidoro Reguera, Madrid, Alianza Universidad; las traducciones del Tractatus Logico-Philosophicus al inglés refieren a la siguiente versión: Wittgenstein, Ludwig, 2009, Tractatus Logico-Philosophicus, trans. C.K. Ogden, Nueva York, Cosimo)

${ }^{20}$ Justamente por ser signos primitivos no pueden ser definidos.
} 
de ser explicado a través de una proposición donde ocurre dicho término. Pero, entender dicha proposición depende a su vez de entender el término que debe ser explicado. Es decir, para entender el término hay que entender la proposición y para entender la proposición ha de entenderse el término. Podríamos decir, como Dummett, ${ }^{21}$ que el significado de los términos primitivos se aprende a través de su uso en proposiciones menos complejas donde aparece y una vez que ya conocemos estos significados podemos usarlos para entender el significado de proposiciones más complejas.

Sin embargo, creo que Wittgenstein piensa que, cuando aprendemos los términos primitivos, lo hacemos observando cómo se usan dichos términos en las proposiciones y la condición para entender la proposición es verla como un todo articulado. En otras palabras, para entender la proposición debe verse cómo se relaciona con los términos y demás proposiciones. Sin embargo, dicha idea de los términos primitivos será abandonada en las Investigaciones, a pesar de que la idea general siga.

Puede decirse: Al nombrar una cosa todavía no se ha hecho nada. Tampoco tiene ella un nombre, excepto en el juego. Esto fue también lo que Frege quiso decir al decir que una palabra sólo tiene significado en el contexto de una oración. ${ }^{22}$

Hemos visto que un tema central en las Investigaciones es aquella conexión entre significado y uso. Tenemos dos versiones con respecto a la noción de significado. La primera

\footnotetext{
${ }^{21}$ Frege (1973), Philosophy of Language.

22 "We may say: nothing has so far been done, when a thing has been named. It has not even got a name except in the language-game. This was what Frege meant too, when he said that a word had meaning only as a part of a sentence". (PI, §49)
} 
de ellas —la débil-dice lo siguiente: es una condición necesaria saber cómo se usa una expresión para saber su significado. Es decir, no es suficiente hacer una correlación entre una cosa y la palabra con el fin de fijar el sentido de dicha palabra. Por ello, las definiciones ostensivas sólo muestran la relación entre la palabra y la cosa, más no da cuenta de su significado, i.e., cómo se usa. Por otro lado, tenemos la fuerte: saber cómo se usa una expresión es una condición necesaria y suficiente para saber su significado. Es decir, sólo cuando sabemos en sentido amplio a qué se refieren las expresiones - si sabemos si la palabra está siendo usada para nombrar un objeto, un rasgo, el color-, podríamos decir que sabemos el significado. No obstante, podría ocurrir que no supiéramos cómo explicar el significado de dicha palabra.

Pero icuántos usos distintos hacemos de la misma palabra! Creo que para saber de qué tipo de uso estamos hablando lo mejor sería confiar en el contexto para saber qué usos son relevantes de acuerdo con la discusión.

\section{4}

\section{Los objetos (simples) y la determinación del sentido en el Tractatus Logico-Philosophicus}

Recordemos que la naturaleza del lenguaje, en el Tractatus, al ser figurativo requiere que el mundo tenga substancia, objetos, una forma fija. Sin sustancia, el sentido de una proposición (Ilamémosle ' $\mathrm{X}$ ') dependería de la verdad de otra (Ilamémosle ' $Y$ '), que a su vez dependería de la verdad de otra (Ilamémosle 'Z'). En última instancia, sin objetos, el 
lenguaje pierde su ancla con la realidad y parece, a lo sumo, condenado a dar vueltas sobre sí mismo. Es por ello que las condiciones semánticas exigen postular objetos como última referencia. El punto es que para que pueden ser figuras de los hechos, las proposiciones del fragmento informativo de nuestro lenguaje deben ser funciones de verdad de proposiciones elementales que a su vez deben ser combinaciones de nombres, que deben nombrar simples. Si figuran de esta manera, las proposiciones pueden tener las condiciones de verdad que tienen ciertos hechos (combinaciones de objetos) en el mundo que las harían verdaderas o falsas.

El Tractatus da la pauta para seguir dicho argumento, ya que nos dice: "La exigencia de la posibilidad de los signos simples es la exigencia de la precisión del sentido". ${ }^{23}$ Es decir, los simples ofrecen la explicación única sobre cómo el lenguaje puede figurar el mundo. Es por ello que el primer Wittgenstein introduce la noción de simples, sin embargo, en las Investigaciones se abandona dicho requerimiento y las objeciones toman dos direcciones.

La primera de ellas se concentra en un ataque al punto de vista de que el lenguaje requiere, por su naturaleza, que haya simples. Wittgenstein trae a cuento dicha crítica, ya que algunos filósofos han tratado a los demostrativos como nombres, incluso como los únicos nombres genuinos. Sin embargo, los demostrativos no son nombres. Por ejemplo, 'esto' no es un nombre, ni siquiera de manera temporal. La idea de los filósofos de tratar los demostrativos como nombres tiene que ver con la idea de que los nombres deben designar simples. En ocasiones, en la definición ostensiva, pronunciamos 'esto' mientras

\footnotetext{
23 "The postulate of the possibility of the simple signs is the postulate of the determinateness of the sense". (TLP: 3.23)
} 
señalamos algún objeto y es común que en el contexto de una oración aparezcan tanto el demostrativo como el nombre en el mismo sitio. La objeción parte de la esencia misma del lenguaje, e.g., las palabras están por los objetos y estas cosas son los significados de las palabras. El siguiente ejemplo muestra precisamente la visión tractariana del lenguaje:

Un nombre propio en sentido ordinario es, pongamos por caso, la palabra 'Nothung'. La espada Nothung consta de partes en una determinada combinación. Si se combinasen de otra manera, no existiría Nothung. Ahora bien, es evidente que la oración 'Nothung tiene un tajo afilado' tiene sentido tanto si Nothung está aún entera como si ya está destrozada, Pero si 'Nothung' es el nombre de un objeto, ese objeto ya no existe cuando Nothung está destrozada; y como ningún objeto correspondería al nombre, éste no tendría significado. Pero entonces en la oración ‘Nothung tiene un tajo afilado' figuraría una palabra que no tiene significado y por ello la oración sería un sinsentido. Ahora bien, tiene sentido; por tanto, siempre tiene que corresponder algo a las palabras de las que consta. Así pues, la palabra 'Nothung' debe desaparecer con el análisis del sentido y en su lugar deben entrar palabras que nombren simples. A estas palabras las Ilamaremos con justicia los nombres genuinos. ${ }^{24}$

Wittgenstein inmediatamente mostrará que el ejemplo confunde el significado de un nombre con el portador del mismo. Es decir, podemos decir, con sentido, que el portador del nombre ha muerto. Sin embargo, no por ello diríamos que el significado del nombre ha

\footnotetext{
24 [I]f "Excalibur" is the name of an object, this object no longer exists when Excalibur is broken in pieces; and as no object would then correspond to the name it would have no meaning. But then the sentence "Excalibur has a sharp blade" would contain a word that had no meaning, and hence the sentence would be nonsense. But it does make sense; so there must always be something corresponding to the words of which it consists. So the word "Excalibur" must disappear when the sense is analysed and its place taken by the words which name simples. It would be reasonable to call these words the real names". (PI, §39)
} 
muerto. ${ }^{25}$ Incluso, podríamos imaginar un juego del lenguaje tal que un nombre pueda ser usado sólo cuando el portador se encuentre presente o, al contrario, que sólo se utilice cuando no se encuentre presente. Por lo tanto, el significado de un nombre no puede ser identificado con su portador.

Existe otra razón que contraviene la postura de que los simples son correlatos de los nombres: que la caracterización que hacemos de 'simple' tiene que ver con un particular marco de referencia o, en términos wittgensteinianos, un juego del lenguaje.

Wittgenstein echa mano de un pasaje del Teetetes el cual tiene gran parecido con las ideas del Tractatus:

Pero es imposible que cualquiera de los elementos primeros quede expresado en una explicación. Respecto a ellos, no podemos hacer otra cosa que nombrarlos, ya que sólo tienen nombre. Sin embargo, si hablamos de las cosas que se componen de éstos, de la misma manera en que ellas son complejas, también sus nombres pueden combinarse y llegar a constituir una explicación, pues la combinación de los nombres es la esencia de una explicación. ${ }^{26}$

Podríamos preguntar, ¿De qué se compone una silla? La respuesta iría acorde a nuestro sistema de clasificación. Podríamos decir que la silla consta de brazos, patas, asiento o de piezas de madera ensambladas o de moléculas o de átomos. La clasificación con la que

\footnotetext{
${ }^{25}$ Habría que tener en cuenta que la objeción va dirigida en contra de aquellas teorías que identifican el significado de un nombre con su portador.

26 "[T]here is no formula in which any element can be expressed: it can only be named, for a name is all there is that belongs to it. But when we come to things composed of these elements, then, just as these things are complex, so the names are combined to make a description (logos), a description being precisely a combination of names". (Theaetetus 202; las traducciones en español del Diálogo Teeteto refieren a la siguiente versión: Platón. Diálogos V. Biblioteca Clásica Gredos)
} 
describiríamos dicha silla depende, en gran medida, de cuáles sean nuestros intereses y de los avances de la ciencia. Es decir, Wittgenstein piensa que no tiene sentido hablar de partes simples de, por ejemplo, una silla.

Hay un argumento ${ }^{27}$ no bien motivado, a mi parecer, que intenta mostrar que los últimos constituyentes de lo compuesto deben ser simples. Tomemos las siguientes dos premisas:

I) Todo compuesto está constituido por simples.

II) Hay simples de los cuales todos los compuestos están formados.

La premisa I es una obviedad, mientras que II es relevante, pero infundada. Es decir, (I) mostraría que por definición un compuesto tiene partes, que estas partes sean simples y no puedan estar compuestas de otras es un asunto distinto. De (II) podemos decir que hay cosas que no pueden dividirse, de lo cual no se sigue que haya cosas o no compuestas de ellas.

Podríamos decir, por ejemplo, que un tablero de ajedrez es compuesto. Sin embargo, podríamos preguntar, ¿compuesto de qué? Podríamos enumerar una y mil maneras en las que decimos que un tablero es compuesto. Pero lo que el argumento intenta mostrar es que usamos la palabra 'compuesto' en muchos modos distintos.

\footnotetext{
${ }^{27} \mathrm{El}$ argumento aparece en: Fogelin, Robert J. (1987), The Arguments of the Philosophers, Wittgenstein, Routledge.
} 
¿Es el color de una casilla de ajedrez simple o consta de puro blanco y puro negro? ¿y es el blanco simple o consta de los colores del arcoíris? ¿Es este trecho de $2 \mathrm{~cm}$ simple o consta de dos trechos parciales de $1 \mathrm{~cm}$ cada uno? ${ }^{28}$

No se sigue de dicho argumento que un tipo de atomismo como el del Tractatus sea falso, sino que sólo se ponen en entredicho aquellas presuposiciones con respecto a la dicotomía entre lo simple y lo compuesto y, por lo tanto, muestra que una teoría que se sirva de dichos motivos puede no ser fructífera. El argumento, muestra, por lo tanto que la noción de simplicidad debe verse como relativa y no absoluta como lo pensaba el autor del Tractatus.

En este capitulo intento examinar las críticas de las Investigaciones al Tractatus. Es decir, se hace un recuento del cambio de paradigma que se da entre lo que suele llamarse el primer y el segundo Wittgenstein. Parte importante de este apartado es mostrar el cambio que se da para la explicación del significado. Sostengo que el Tractatus elabora la explicación general teniendo como base las condiciones de verdad, mientras que las Investigaciones intentan explicar la noción misma de significado a partir de nociones como uso, reglas y, de manera más general, desde las condiciones de aseverabilidad. En particular, el tema a tratar es el problema de seguir una regla y considero que en la etapa del Tractatus aparecen ejemplos de dicha noción. La que me parece más relevante es la de definición ostensiva, ya que muestra un claro ejemplo de cómo comprendemos la explicación del significado de una palabra y el uso en circunstancias futuras. Esto es, las

\footnotetext{
28 "Is the colour of the square on a chessboard simple or does it consist of pure white and pure yellow? And is white simple, or does it consist of the colours of the rainbow? Is the length of $2 \mathrm{~cm}$. simple, or does it consist of two parts, each $1 \mathrm{~cm}$. long?” (PI, §47)
} 
definiciones ostensivas son reglas que nos indican cómo captar el significado de algunas palabras. En el capítulo 2, Antirrealismo: Kripke y el argumento escéptico sobre el seguir una regla, se pondrá en tela de juicio el problema de seguir una regla y la noción de comprensión en general. 


\section{Antirrealismo: Kripke y el argumento escéptico sobre el seguir una regla}

El debate que gira en torno a la comprensión lingüística puede ser visto, por lo menos, desde dos perspectivas. En primer lugar, tenemos la postura realista que afirma que hay hechos ${ }^{29}$ sobre lo que queremos decir cuando utilizamos un signo, palabra o término; es decir, que hay evidencia, $p$. ej., estar en cierto estado mental o algún rasgo de mi conducta externa que justificaría nuestros usos correctos. Por otro lado, tenemos la vertiente antirrealista, defendida por Kripke, que sostiene que no hay hechos que justifiquen mi querer decir algo con un signo. Entonces, la dicotomía podría plantearse de la siguiente manera: hay quienes defienden que hay hechos mediante los cuales es posible dar cuenta de la comprensión lingüística sin recurrir más que a uno mismo. Y existen los que creen, como Kripke, que de manera individualista no podemos dar cuenta de la comprensión, sino sólo apelando a una comunidad de hablantes en interacción con el mismo hablante.

En otras palabras, la conclusión kripkeana del argumento escéptico será que el querer decir algo mediante un término, palabra, etc., es factualmente vacío, ya que no hay hecho alguno que determine o que constituya lo que se quiere decir al usar cierto signo.

29 "Hecho" puede entenderse, por lo menos, de dos maneras. En primer lugar, que una entidad posea propiedades que se le adjudican o, en segundo lugar, que dicha entidad se encuentre en cierta relación con una o más entidades. 
El argumento parte de la premisa de que el querer decir algo y los usos que hacemos del mismo es normativo, i.e., prescribe criterios de evaluación de los usos que se hacen. Es decir, la comprensión es normativa con respecto al uso.

Tenemos, por lo menos, dos maneras distintas de entender cómo funciona el curso de una acción. En primer lugar, tenemos un criterio que podríamos denominar descriptivo y que involucra meramente un recuento de cómo suceden las acciones dentro de determinado lapso. En segundo lugar, hay otro criterio distinto al primero, y en oposición a él, que es el prescriptivo o normativo. Es decir, dada una instrucción, cierta orden o cierto adiestramiento uno aprende que tales y cuales acciones se deben llevar a cabo de tal modo y no de algún otro. Es decir, la normatividad impone criterios de uso. Para Kripke la comprensión y la normatividad van de la mano, él piensa que el criterio objetivo lo da una perspectiva de tercera persona.

Este apartado se basará en una lectura exegética de lo que plantea Kripke. En lo personal, creo que una lectura detallada del texto, Wittgenstein: On Rules and Private Language, nos proporcionará una idea más clara de cómo debemos entender los pasajes de las Investigaciones Filosóficas que versan sobre el problema de seguir una regla y la normatividad asociada al lenguaje. Aquí no pretendo abundar en la discusión sobre si la exégesis que hace Kripke de Wittgenstein es, o no, fiel al argumento de seguir una regla. 


\section{1}

\section{La paradoja Wittgenstein/Kripke}

En §201, Wittgenstein dice:

Nuestra paradoja era ésta: una regla no podía determinar ningún curso de acción porque todo curso de acción puede hacerse concordar con la regla. La respuesta era: si todo puede hacerse concordar con la regla, entonces también puede hacerse discordar. De donde no habría ni concordancia ni desacuerdo. ${ }^{30}$

Según Kripke, la paradoja es el eje sobre el cual giran las Investigaciones Filosóficas, ya que se propone una nueva forma radical de escepticismo. En este apartado abordaré la manera en que Kripke entiende y resuelve el problema.

En primer lugar, da un ejemplo del seguir una regla para la aritmética, en particular, para la adición. ${ }^{31}$ Nos dice que imaginemos a un sujeto (S1) el cual es un hablante competente de la lengua española y que se encuentra, particularmente, familiarizado con el lenguaje aritmético. Podríamos decir, casi con certeza, que (S1) usa el signo "+" para referirse a la función aritmética de la adición (más). Siempre que usa "+" piensa en la regla de la adición. También supongamos que (S1) en cuestión ha sumado hasta ahora cualquier par de números naturales, es decir, ha hecho una serie finita de sumas. Cualquiera que

\footnotetext{
30 "This was our paradox: no course of action could be determined by a rule, because every course of action can be made out to accord with the rule. The answer was: if everything can be made out to accord with the rule, then it can also be made out to conflict with it. And so there would be neither accord nor conflict here". (PI, §201)

${ }^{31}$ Es importante recalcar que la regla que tiene Kripke en mente es la semántica. Lo que interesa a Kripke es investigar cómo hacemos para que la regla nos indique cómo actuar. Es decir, cómo nos guía la regla, para saber aplicar el significado en casos futuros.
} 
observe a (S1) podría pensar que él podría aplicar la misma regla a cualquier caso que se le presente en el futuro. Esto es, a pesar de que (S1) haya hecho sólo una serie finita de sumas, éste se ve como si fuera guiado a dar el siguiente paso, es decir, aplicar la regla de manera correcta en los casos subsecuentes. Por lo tanto, pareciera que la captación de la regla le permite computar las siguientes sumas, ya que sigue el proceso de adiestramiento que ha interiorizado. Por lo tanto, (S1) tiene la creencia de que la regla interiorizada determinará sus usos correctos. Es decir, no significa que dé un salto injustificado en cada ocasión en la que se le presenta una adición. Actúa conforme lo ha venido haciendo y es por esa misma captación de la regla que los resultados están justificados.

Podemos describir el curso de (S1) de la siguiente manera: si tiene la intención de querer decir adición mediante el signo “+", entonces él mismo debe tener una asignación determinada de cierto significado y, por lo tanto, cada que se le aparezca una adición él sigue las consideraciones (reglas, criterios) a las que se ha comprometido mediante la asignación de cierto significado a cierto signo. En otras palabras, si para cada signo (S1) asocia cierto contenido y sólo éste, entonces para proseguir de manera correcta debe respetar la asignación de dicho contenido para dicho signo.

La noción de significar y/o querer decir algo resulta a primera vista parte del sentido común. Partimos de la intuición básica de que para que podamos querer decir algo mediante un signo hemos de comprometernos con seguir ciertas normas que aprehendemos una vez que hemos captado la regla. Esto es seguimos nuestras inclinaciones. A pesar de que podamos equivocarnos en el uso adecuado de cierto signo en particular, la captación de la regla es la que nos permite guiar nuestros usos futuros de la 
palabra, en los casos donde asociamos ese signo con ese único contenido. La comunicación exitosa entre hablantes competentes nos invita a pensar que al querer decir algo no damos respuestas arbitrarias, es decir, normalmente no hablamos sin seguir pautas, reglas, criterios que regulen nuestros usos. Dicho de otro modo, la captación de regla o captar el significado de la palabra nos compele a dar las respuestas que corresponden a un número indefinido de nuevos casos en el futuro. Por un lado, la noción de significado debe ser finita para que podamos capturarla y por otro lado debe ser infinita en el sentido de que implica una infinidad de normas de uso.

Kripke nos propone una situación hipotética en la que (S1) debe sumar 68 a 57 . Se supone que él nunca ha hecho sumas que involucren números iguales o mayores a $57 .{ }^{32}$ Lo que nos interesa es que aquí, (S1) asocia la palabra "más" con la función aritmética de la adición. Entonces, se le plantea la siguiente cuestión: “¿68 + 57 = _ ?”, a lo que él responde con las palabras "ciento veinticinco". (S1) actúa conforme lo ha venido haciendo tiempo atrás, por lo tanto, tiene plena confianza en que la respuesta que ha dado es la correcta.

Sin embargo, nos encontramos con un escéptico extravagante, llamémosle P. Éste lo interpela y le pregunta: ¿Cómo sabes que has dado la respuesta correcta? Nuestro sujeto nos dice que él usó “+” como siempre lo había hecho, por lo tanto, él cree que está en lo cierto. Y, nos dice que, en el pasado sumó siempre que se le presentaba el signo "+". Por lo

\footnotetext{
${ }^{32}$ Lo importante es que haya un límite finito para el número de usos pasados; no importa tanto cual sea este límite.
} 
tanto, actúa del mismo modo. Es decir, (S1) interpreta "+" de tal modo que hay algo ${ }^{33}$ que él interioriza y que su captación de ese algo le permite interpretar correctamente a "+" de modo que dé "ciento veinticinco" como respuesta. ${ }^{34}$ Nuestro escéptico entra en escena y le formula la siguiente pregunta: “¿Cómo sabes que en el pasado no quisiste decir con '+', por decir algo, cuadición ${ }^{35}$ y no adición?" El escéptico le dice que cuando uno formula la siguiente operación " $68+57$ ", el resultado que debe arrojar es “ 5 ". Éste procede del modo en que reaccionaría ante la función aritmética de la cuadición. Probablemente, nos causaría bastante desconcierto tal proceder, ya que no obedece al sentido común y, de hecho, lo contraviene. Sin embargo, podríamos pensar que es un hablante divergente. A pesar de que la hipótesis sea descabellada, no parece ser incoherente.

Las funciones de la cuadición y la adición, podríamos ponerlas del modo siguiente: $x * y=x+y$, si $x, y<57$ $=5$, en otro caso.

La definición viene a dar cuenta de que cuando aparecen como argumentos números menores a 57, entonces el resultado será el que comúnmente asociamos al sumar y, por el contrario, cuando dentro de la función aparezcan como argumentos números mayores o iguales a 57, entonces el resultado que arrojará la cuadición será 5 . La cuadición es una función divergente asociada con el símbolo "+".

\footnotetext{
${ }_{33}$ Pensemos ese "algo" como un estado mental asociado a la comprensión.

34 Justamente ese "algo" es el blanco del ataque escéptico. Es decir, el escéptico kripkeano va a dudar sobre la existencia de ese "algo" entendido como hecho constituyente del querer decir.

${ }^{35}$ El signo de cuadición se simbolizará de ahora en adelante con *.
} 
En principio, hemos de explicitar ciertas reglas que son básicas para que la formulación de la hipótesis escéptica corra. Tenemos, en primer lugar, que ambos tienen un lenguaje en común. En otras palabras, el escéptico no pone en duda el uso presente de "más", ya que él admite que de acuerdo con su uso presente de "más" la respuesta "ciento veinticinco" es correcta. Es decir, (S1) no falla en un error de cálculo, no se equivoca sobre su uso presente de "+". La tesis que pone en duda el escéptico es que el uso presente y el uso pasado mantengan el mismo significado. Ambos usan "más" en el presente con el mismo contenido. El problema a pesar de ser introducido con ejemplos de la aritmética, no es un problema, en sentido estricto, aritmético. Más bien es un problema que subyace al contenido semántico de los signos y que se puede aplicar a cualquier término significativo del lenguaje. La hipótesis correctamente entendida cuestiona el cambio en el significado que se asocia con el uso. La duda se encuentra en los significados pasados.

Por lo tanto, si nuestro sujeto no está en condiciones de poder justificar su uso de adición (más) mediante el signo “+”, entonces ¿cómo es posible justificar su uso de más? Y, ¿cómo justificar que no quiso significar cuás ${ }^{36}$ en lugar de más?

Las objeciones del escéptico son las siguientes:

i) El escéptico duda que haya algún hecho que pruebe que se quiso sumar y no cuasumar.

ii) Duda que se posea razón alguna para responder 125 en lugar de 5.

iii) Duda de que el uso pasado concuerde con el uso presente respecto al significado del hablante.

\footnotetext{
36 "Cuás" está por la función de la cuadición, mientras que "más" está por la de la adición.
} 
De este modo, el escéptico sostiene que no hay hecho alguno, mental o conductual, que establezca que se quiso decir sumar en vez de cuasumar. ${ }^{37}$ No hay limitaciones en los hechos que (S1) pueda citar para refutar al escéptico, es decir, cabe la posibilidad de citar un hecho de su conducta que pudiera observar un espectador externo o un hecho interno que conozca por medio de introspección. La hipótesis se torna mucho más radical cuando el escéptico afirma que aun si Dios fuera quien mirara, dada su omnisciencia, todos los hechos, no encontraría uno que justificara su uso de "más". La cuestión es que no hay tales hechos.

Kripke plantea que podríamos refutar el reto escéptico mediante la siguiente estrategia. (S1) se provee de una gran cantidad de canicas. Para ello, contamos primero el conjunto de canicas $Y$ después contamos las canicas del segundo conjunto X. El paso a seguir sería juntar los dos conjuntos de canicas y contar el número total de canicas. El resultado en este caso sería la suma de $X+Y$. Según esta estrategia, podríamos dirimir la confusión sobre si (S1) quiso significar más o cuás, es decir, dado que está contando no surge la problemática de la indeterminación de qué significado asoció con el signo “+”. Sin embargo, el escéptico contraataca con la siguiente objeción: la palabra "contar", al igual que la palabra "más", se ha aplicado sólo a una serie finita de casos. Por lo cual, el desafío

\footnotetext{
${ }^{37}$ En particular, creo que el escéptico tiene en mente una asunción que es de suma importancia para entender mejor el argumento. Dicha asunción es que para que una oración sea verdadera o falsa debe, necesariamente, tener condiciones de verdad, es decir, aquella contraparte en el mundo que hace verdadera o falsa dicha oración. Si (S1) quiere decir adición mediante el signo “+", entonces, según lo que asume el escéptico, debe haber un hecho que haga verdadera a la oración: “(S1) quiere decir adición mediante el signo ' +'". Donde dicha oración describe un estado de cosas real. En caso contrario, que sea falsa, entonces describe un posible estado de cosas. Kripke quiere convencernos de que en las Investigaciones, Wittgenstein crítica su anterior concepción del significado en términos de condiciones de verdad.
} 
escéptico se sigue manteniendo; ya que no tendría garantía de que su uso de "contar" en el pasado sea el mismo que ahora hace del mismo. En particular, podríamos pensar que con contar antes había querido significar cuontar. ${ }^{38}$ Parece que cualquier estrategia que desarrolle (S1) podría ser bloqueada por el escéptico, ya que no funciona recurrir a otra palabra para determinar el uso correcto de otra palabra - no podríamos tratar de esclarecer el significado de "más" a través de la clarificación de "contar"- Esto es justamente lo que Wittgenstein rechazaba: explicar una regla en función de una regla más básica; en particular, postular una regla para interpretar una regla. La estrategia sostenida por el escéptico puede recurrir incluso a cualquier regla más básica que podamos concebir. La circularidad aquí se hace explícita. Esto es, las justificaciones deben parar en algún punto -donde lo que nos quede sea una regla que no sea reducible a ninguna otra. Esto es, interpretar una regla en función de otra da como resultado un regreso al infinito.

El reto que nos plantea el escéptico es principalmente un problema lingüístico, ya que trata sobre la comprensión y el modo en que las palabras significan lo mismo en momentos distintos, cómo logramos tener certeza de que usamos las palabras tal y como las empleábamos en el pasado. No es imposible pensar que ahora nos equivocamos con respecto al uso que actualmente les damos. Hemos de hacer hincapié en que hacemos uso de un signo para querer decir algo de manera finita, esto es, dada nuestra finitud no podemos saber (asegurar) que aplicamos la misma regla de manera correcta. El problema

\footnotetext{
38 El significado de "cuontar" no es importante, simplemente son estipulaciones para respaldar la hipótesis escéptica. Es decir, es el mismo símbolo pero asociado a significados distintos.
} 
de una concepción individualista de la comprensión parece ser incompatible con nuestro conocimiento del significado.

Dicho de otro modo, podríamos estar dando significados distintos a los mismos símbolos. No es posible, según el escéptico, citar un hecho individual que dé la pauta para justificar que usamos los mismos términos en el presente tal y como los usábamos en el pasado. Aprendemos una regla y la aplicamos de manera finita, pero es posible aplicarla a un infinito potencial de casos. Entonces, ¿cómo nuestras mentes finitas pueden dar reglas que se supone se aplican a una infinidad de casos? ¿Qué es lo que constituye la regla? Y ¿qué es lo que justifica los usos correctos de las reglas?

Sin embargo, este problema podemos hacerlo extensivo y ver cómo funciona en áreas distintas a la matemática, ya que, según el escéptico, se aplica a todo el lenguaje; dicho sea de paso, no es un problema que sea exclusivo de la aritmética. Así pues, Kripke nos ofrece otro ejemplo, a saber: hemos aprendido la palabra "mesa" y lo aplico a una cantidad finita de objetos en el pasado. Entonces, cuando aplicamos en casos nuevos la palabra mesa en realidad podríamos haber querido significar cua-mesa. Parece ser que, si la hipótesis escéptica es cierta, podríamos estar confundiendo los significados de las palabras y no hay hecho que nos dé evidencia para refutar al escéptico. Del mismo modo, procedemos con los colores. Tenemos noción de lo que es el color verde, sin embargo, podríamos estar aplicando ahora dicho predicado a objetos que en el pasado llamábamos verdules. $^{39}$ El problema, como podemos observar, sigue siendo el mismo. La cuestión

${ }^{39}$ Green and grue, respectivamente. Según lan Hacking, hay una analogía entre el nuevo enigma de la inducción, planteado por Nelson Goodman y el escepticismo sobre el significado que plantea Kripke. Al parecer, "verdul" puede ser utilizado, tal como lo hace Kripke, para plantear el problema en términos del 
parece ser complicada, ya que el escéptico podría interpretar el significado de color por cua-

color y así de manera indefinida. Lo mismo aplica para el lenguaje de sensaciones. Pues, ¿cómo podríamos determinar el significado de un dolor? o ¿cómo podríamos saber si un niño utiliza con corrección la palabra "dolor"? En consecuencia, el lenguaje resultaría no tener significado, sino varios y la cadena de interpretaciones se podría dar ad infintum. Kripke quiere decir que si no tenemos evidencia a la mano que justifique nuestros usos cuando queremos decir algo con un signo, entonces, como consecuencia del argumento

significado. El problema de Goodman puede ser caracterizado del siguiente modo: ¿por qué no predecir que la hierba, que ha sido verdul en el pasado, será verdul en el futuro? A diferencia del problema de Kripke/Wittgenstein: ¿Cómo saber que en el pasado no quise decir verdul mediante "verde" de modo que ahora debo llamar "verde" no a la hierba, sino al cielo? En primer lugar, creo que, a pesar de tener un gran parecido, en esencia, el problema es distinto. El problema de Goodman está enfocado en la inducción, es decir, dado un conjunto finito de premisas (observaciones) particulares, no podemos concluir una proposición general que se derive de aquellas premisas. Por ejemplo, hemos observado y hemos llevado (en una libreta) una serie de largas anotaciones por cada día que hemos visto que sale el sol, sin embargo, no podemos asegurar que saldrá mañana. Es decir, lo que se cuestiona es el nexo entre eventos pasados con relación al futuro. Goodman formula el nuevo enigma de la inducción de la siguiente manera: supongamos que todas las esmeraldas que hemos observado antes del tiempo futuro $T$ son verdes. Dicha regularidad nos insta a pensar que todas las esmeraldas son verdes. Goodman nos exhorta a pensar el predicado "verdul" definido del siguiente modo: un objeto es verdul si y sólo si ha sido examinado antes de un tiempo específico $T$ y es verde o no ha sido examinado antes de $T$ y es azul. Por lo tanto, las esmeraldas examinadas antes de $T$ son verdules $y$, en este sentido cualquier evidencia a favor de que las esmeraldas futuras son verdes es también una evidencia a favor de que son verdules y, a fortiori, de que son azules. De este modo nos es lícito concluir a partir de las evidencias recolectadas que todas las esmeraldas son verdes, como concluir que son verdules. Sin embargo, el apego al sentido común, dicta que nos inclinaríamos a suponer que la conclusión válida es aquella que sostiene que las esmeraldas son verdes. Entonces, recapitulando, el nuevo enigma de la inducción se enfrenta con el problema de cómo hacer válidas las inferencias inductivas, i.e., por qué nos inclinamos por una hipótesis más que por la otra. Goodman sostiene que la respuesta descansa en la noción de "atrincheramiento" Sin embargo, en esta nota sólo enuncio el problema y cómo se distingue del problema del presente capítulo. Parece ser que, para Goodman, la extensión de "verde" "verdul" es conocida y, por lo cual, no trata el problema del significado que es esencial a la exposición kripkeana. La paradoja escéptica presentada por Kripke, a diferencia de Goodman, radica en primer lugar en cuestionar el uso pasado de una palabra con el uso presente que se hace de la misma. En segundo lugar, ¿qué constituye querer decir algo con esa palabra? y ¿cómo justifica el uso de esa palabra en el pasado, así como en el futuro? 
escéptico, la idea misma de significado se desvanece en el aire y, por lo tanto, el lenguaje se ve como carente de significado.

Entonces, ¿cómo saber que utilizo el lenguaje como en ocasiones anteriores? Así pues, en el caso de nuestro ejemplo matemático, cuando respondo a $68+57$, ya sea 125 o 5, no puedo tener justificación ni por la una ni por la otra. Por lo tanto, no puedo justificar mi querer significar la suma o la cua-suma, de donde no habría algo que distinga el significado de más y cuás. Esto es precisamente lo que Kripke llama la paradoja escéptica.

Hasta ahora, tal como Kripke lo presenta, podría pensarse que el reto que se propone es un reto epistémico; sin embargo, el reto comprendido de manera amplia es un reto metafísico o mejor dicho constitutivo. Es decir, a pesar de que a través de la exposición kripkeana aparezca como un reto epistémico (¿cómo puede uno saber que quise decir más y no cuás?). El problema que subyace a la paradoja es un reto metafísico, i.e., al parecer no hay nada que constituya el significado. Del mismo modo, Boghossian dice: "el problema que he subrayado es constitutivo, no epistemológico. El tema central es la posibilidad del significado, no nuestro conocimiento de él" ${ }^{40}$

Dadas las características del reto, hemos visto que ambas hipótesis, si (S1) quiso decir más o cuás, son compatibles. Pero dado que no hay evidencia de mi historia mental, conductual o cerebral que distinga qué se quiso decir, no podemos pensar que sea un reto que tenga que ver con cómo conocemos o distinguimos una función de otra. El escéptico

\footnotetext{
${ }^{40}$ Boghossian, P., The Rule Following Considerations, p. 515 “For Kripke's problem appears to be essentially epistemological in character -it concerns a speaker's ability to defend a particular meaning ascription; whereas the problem I have outlined is constitutive, not epistemological - its topic is the possibility of meaning, not our knowledge of it".
} 
concluye que no hay hechos que constituyan, es decir, que determinen que se quiso decir adición o cuadición. Por lo tanto, querer decir algo con alguna palabra es factualmente vacío.

Por lo tanto, si se quiere responder al reto, hay dos condiciones que debemos satisfacer, a saber, una condición constitutiva y una condición epistemológica. ${ }^{41}$ La primera de ellas, la C.C., nos dice que debe haber un hecho acerca de nuestro sujeto que determine que uso "+" para significar adición y no cuadición. Es, pues, la justificación de querer decir más y no cuás. La segunda de ellas, la C.E., nos dice que debe haber alguna evidencia asociada con el hecho de su comprensión de "+" y accesible a nuestro sujeto en cuestión. Es decir, nuestro sujeto debe ser capaz de justificar sus creencias de cómo entiende "+". Esto es, ¿cómo es que está justificado a responder 125 y no 5 ?

Como hemos visto, la comprensión lingüística es una cuestión normativa, ya que involucra el uso y seguimiento de reglas. Entonces, las condiciones antes enunciadas deben ser traducidas en términos normativos. Las condiciones traducidas en términos de normatividad deben dar cuenta de:

(C.C.) Las normas de uso asociadas con las que nuestro sujeto entiende adición.

(C.E.) La justificación de las normas asociadas de la condición constitutiva para sustentar las creencias de nuestro sujeto donde "+" significa más. ¿Qué justificación tiene nuestro sujeto para pensar que éstas son las normas lingüísticas para la función “+”?

\footnotetext{
41 De ahora en adelante, la abreviatura correspondiente será la siguiente: C.C. condición constitutiva y C.E. condición epistemológica.
} 


\section{2}

\section{Posibles soluciones para el reto escéptico}

A lo largo del texto de Kripke, Wittgenstein on Rules and Private Language, se dan algunas soluciones para brindar una respuesta al reto escéptico.

En primer lugar, examinaremos la respuesta que surge a partir de los análisis disposicionales con la publicación de The Concept of Mind ${ }^{42}$. Dichos trabajos nos instan a pensar que el querer decir algo con un signo puede verse como teniendo una disposición para la conducta. Es decir, tener la disposición a contestar de una u otra forma. Podríamos caracterizar, grosso modo, el disposicionalismo de la siguiente manera: “A veces atribuimos a un objeto propiedades disposicionales, por las cuales entendemos que ciertos contrafácticos que involucran al objeto son verdaderos. Por ejemplo, decimos que "una sustancia sólida A es soluble en agua sólo si un trozo de A que fuera arrojado en agua se disolviera en ella". ${ }^{43}$ Diríamos de alguna persona que es inteligente sólo si creyéramos en la verdad de algunos contrafácticos cuando se comportara de tal y cual manera. Esto es, por "disposición" hemos de entender una propiedad que se define de acuerdo con el comportamiento de algún objeto en circunstancias actuales y/o contrafácticas. La ventaja que nos ofrece dicha postura es que no sólo nos explica cuáles fueron los usos pasados que

\footnotetext{
42 Gilbert Ryle (1949)

${ }^{43}$ Mota Pinto (2009: 34), Escepticismo del significado y teorías de conceptos.
} 
(S1) quiso decir mediante "+", sino que también nos da una explicaciónque conecta usos pasados y usos futuros que (S1) pudiera hacer de dicho signo, por lo cual, podríamos pensar que dicha empresa filosófica resulta promisoria.

En el caso concreto de la adición, podríamos decir lo siguiente: Supongamos que se le plantea a nuestro sujeto “ $\mathrm{ix}+\mathrm{y}=\ldots$ _ ? ? Y él respondiera, por decir algo, "w", entonces " $w=x+y "$. La disposición que está en juego es la de la suma y que nuestro sujeto tiene la disposición a sumar, en particular, cuando se le pregunta por la suma de $68+57$. Lo que pretende el criterio disposicionalista es que podamos leer cuál es la función que se quiere decir mediante cierto signo.

Sin embargo, hay, por lo menos, cuatro objeciones. La primera tiene que ver con que el criterio disposicionalista malentiende el problema, i.e., dado que ha hecho sólo una serie finita de sumas en el pasado, (S1) tuvo la disposición de querer sumar y no cuasumar. Él en el pasado siempre tuvo la disposición de responder con la suma. Sin embargo, ¿cómo sabe que ahora no está malinterpretando las disposiciones que tenía? Es decir, ¿cómo sabe que ahora cuando se le presenta el signo de la adición no tiene en mente la disposición de la cuadición? Parece ser que el hecho que nos proporciona el análisis disposicional no satisface la condición básica que debe cumplir tal hecho, no nos dice qué hay que hacer en los casos que se nos presenten en el futuro. Si decimos que (S1) en el pasado tenía la disposición a sumar y, ahora en el presente, la sigue manteniendo podríamos objetar diciendo que del hecho de que en el pasado haya tenido la disposición a querer decir la adición no se sigue que en el presente mantenga la misma disposición y, por lo tanto, quiera significar la misma función. Es decir, no puede justificar su creencia presente de que quiere decir adición 
mediante la hipótesis de sus disposiciones pasadas. El escéptico aquí argumenta que (S1) no lleva un registro que detalle su historia mental, por lo cual, piensa que la hipótesis entre haber querido decir más y cuás se sigue sosteniendo. Ambas opciones son igualmente compatibles y no habría modo de determinar si se quiso decir una función en vez de otra.

Lo que el disposicionalista desea hacer, según Wittgenstein, ${ }^{44}$ es ofrecer un criterio que dice que cualquier cosa que parezca correcta es correcta, es decir, eso sólo significa que no podemos hablar de corrección. Dicho criterio parece remitirnos a una única posible respuesta: si se tiene la disposición de actuar de tal modo, entonces no podemos errar en la respuesta. Tendríamos como resultado que deberíamos dar una y sólo esa respuesta.

La segunda de las objeciones tiene que ver con la finitud de las disposiciones. Siempre puede haber cualquier par de números lo suficientemente grandes para que no alcancemos a captar el resultado de la suma. Es decir, no es cierto que, si se me pregunta por una suma, no importando lo grandes que sean los números, yo vaya a dar la respuesta correcta. En el caso límite, podríamos decir que hay números lo suficientemente grandes para que uno muera antes de poder siquiera responder. Kripke afirma que ni siquiera al hablante más competente es posible atribuirle las disposiciones suficientes para que sea capaz de hacer cómputos de funciones que involucran números demasiado grandes. Sin embargo, el disposicionalista argumenta que la objeción sólo corre dado que el objetor toma una versión demasiado cruda del disposicionalismo; esto es, una versión idealizada ceteris paribus podría aclarar la cuestión. Por lo tanto, en su afán de responder al escéptico podría esgrimir un contraargumento como el siguiente: en condiciones ideales donde uno

\footnotetext{
${ }^{44} \mathrm{PI}, \S 258$.
} 
tuviera los requisitos indispensables para hacer sumas lo suficientemente grandes - como una vida lo suficientemente saludable, las capacidades adecuadas, etc. - , uno podría responder dichas sumas. Supongamos que se le plantea a (S1) la pregunta por una suma cuyos números fueran lo suficientemente grandes para que logre captarlos, además concedamos que tiene la intención de sumar y que fuera a satisfacer su intención. Entonces, si se le preguntara por " $x+w$ " siendo $x$ y w números grandes, respondería con la adición de tales números y no con la cuadición. Sin embargo, nos diría el escéptico que, a pesar de su intento, su explicación es circular. De este modo, nos dice Kripke:

Semejante condicional contrafáctico es aceptablemente verdadero, pero no sirve de ayuda contra el escéptico. Presupone una noción previa: mi tener una intención de querer decir una función en vez de otra mediante “+”. Es por virtud de un hecho de este tipo acerca de mí por lo que es verdadero el condicional. Pero, por supuesto, el escéptico está poniendo en tela de juicio la existencia precisamente de tal hecho. Hay que especificar su naturaleza, si se quiere hacer frente al reto escéptico. Si se acepta que quiero decir adición mediante "+", entonces por supuesto, si yo actuase en concordancia con mis intenciones, respondería, dado cualquier par de números a combinar mediante "+" con su suma. Pero igualmente, si se acepta que quiero decir cuadición, si yo actuase en concordancia con mis intenciones, respondería con la cuasuma. ${ }^{45}$

\footnotetext{
45 "Such a counterfactual conditional is true enough, but it is of no help against the sceptic. It presupposes a prior notion of my having an intention to mean one function rather than another by " + ". It is in virtue of a fact of this kind about me that the conditional is true. But of course the sceptic is challenging of just such a fact; his challenge must be met by specifying its nature. Granted that I meant addition by " + " then of course if I were to act in accordance with my intentions, I would respond, given any pair of numbers to be combined by
} 
Es decir, la idealización ceteris paribus del criterio disposicional falla no porque el condicional contrafáctico sea falso, sino porque presupone de entrada querer decir una función en vez de otra, por lo cual la circularidad se hace evidente.

La tercera objeción tiene que ver con el problema del error. La mayoría de nosotros cuando nos vemos inmersos en un proceso de desarrollar sumas, restas, etc., que involucran números mayores a dos dígitos es posible que tengamos la disposición a equivocarnos. A veces cuando hacemos sumas, p.ej., "48 +58", podríamos dar como respuesta "96", sin embargo, podemos percatarnos que se nos olvidó por error anotar la cifra que llevábamos y de este modo, la respuesta correcta sería 106. A veces tenemos la disposición a equivocarnos, es decir, decimos que hubo un error de cálculo. Entonces, tanto para los que calculan de manera correcta y para los que lo hacen de manera correcta el signo “+" significa adición. Según entiendo, el disposicionalista, sugiere que al percatarnos del signo "+" nosotros seríamos capaces de saber cuál es la función que queremos decir mediante dicho signo. Cuando aparece tal signo, la disposición asociada que tengo de usarlo de tal modo debe dar el resultado correcto y no habría manera en que nos equivocáramos. Sería tal como dar una respuesta que no coincidiera con la función que quise decir. Por lo tanto, esto muestra que el disposicionalismo se queda corto al explicar el problema del error.

\footnotetext{
" + ", with their sum; but equally, granted that I mean quaddition, if I were to act in accordance with my intentions, I would respond with the quum". (1982:28)
} 
La cuarta y última de las objeciones al disposicionalismo gira en torno a su incapacidad de dar cuenta de la normatividad de la comprensión. El disposicionalista ha dado una respuesta que radica en una versión descriptiva, esto es, si se nos presenta la siguiente operación: “68 + 57" y si con el signo "+" quisimos decir adición, entonces responderemos "125". Sin embargo, lo crucial no es que si queremos decir mediante "+" responderemos " 125 ", sino que, de acuerdo con el significado, si nos proponemos a concordar con nuestros usos pasados, entonces debemos responder "125". Lo que se quiere resaltar es que la acción que emprendemos en el futuro es normativa, no descriptiva. Debemos pues saber qué debemos hacer en los casos futuros donde se nos presente tal signo. Por lo tanto, Kripke reniega de que la solución disposicional, en cualquiera de sus versiones, rescate la relación entre la comprensión de un concepto y su aplicación correcta. Lo que hacen los disposicionalistas es ofrecer una explicación descriptiva y no normativa, en tanto que la necesaria es la segunda. Debemos recalcar que si el problema de la normatividad, tal como lo presenta Kripke, es genuino, entonces plantea una de las objeciones más fuertes en contra del disposicionalismo. Es decir, dichas posibles respuestas al reto escéptico se plantean únicamente en términos de lo que haría un sujeto dadas tales y cuales circunstancias y no de lo que debería o se encontraría autorizado a hacer. El disposicionalismo puede ser completamente descrito sin incluir términos que sean normativos. Sin embargo, el querer decir algo con un signo y los usos que hacemos del mismo necesariamente requiere normatividad. Esto es, ser capaces de evaluar el uso correcto e incorrecto de un signo. Recapitulemos, la primera objeción no nos dice como evitar la confusión entre querer significar la suma o la cua-suma. La segunda de ellas, tiene 
que ver con la finitud, esto es, hay números tan grandes que no podríamos sumar, podríamos morir antes de haber hecho la suma. La tercera tiene que ver con el problema del error, es decir, en ocasiones estamos nos vemos dispuestos a fallar en las sumas y el disposicionalismo no nos dice cómo evitar dicho errores y la cuarta tiene que ver con que estar dispuestos a responder de tal o cual modo, no nos dice cómo debemos actuar.

Por otro lado, tenemos un segundo intento de solución que gira en torno a los hechos irreductibles. ¿Por qué no argumentar que querer decir adición con "más" es una experiencia irreductible? Estaríamos pensando en una experiencia que tendría ciertas características cualitativas, i.e., aquellas que son específicas de la experiencia subjetiva, aquellas que pertenecen únicamente a querer decir adición y sólo a esa función, es decir, el "cómo se siente tal y cual sensación". ${ }^{46}$ Cuando queremos decir la adición y/o cuadición con un signo, entonces tendríamos algo que sería característico como picor, un dolor de cabeza, náuseas o algo como el ver rojo, situaciones que cada uno de nosotros conoce por medio de la introspección. Claro, esto presupondría que el querer decir adición mediante "+" es una experiencia irreductible e introspectable. El hecho de que se quiera decir algo con un signo estaría respaldado por las cualidades intrínsecas de haber querido decir tal y cual con dicho signo. Supongamos que, en el pasado, siempre que se me presentaba el signo "+", yo quería decir adición, ya que había una única experiencia con cierto qualia que es característico de la comprensión de este significado y de ninguna otra. Los defensores de esta postura tendrían que asumir que las cualidades de las experiencias irreductibles que

\footnotetext{
${ }^{46}$ Estoy pensando en Nagel, en particular, en su artículo de 1974, "What is it like to be a bat", The Philosophical Review 83 (4): 435-450.
} 
son asociadas a la función de la cuadición difieren de las cualidades de las experiencias que asocian a la función de la adición.

Sin embargo, el escéptico vuelve a poner trabas a dicha solución. La primera objeción que podemos observar es que incluso si tuviéramos un dolor de cabeza o algún estado interno que nos indique que pensamos en "+", ¿cómo sabríamos si deberíamos responder 5 o 125? Es decir, esa experiencia del significado del término no nos dice qué respuesta debemos dar. Jamás (S1) había hecho sumas que involucraran números mayores o iguales a 57, entonces ¿cómo sabría si debe responder 5 o 125? El escéptico afirma que es igualmente compatible tener una experiencia u otra, ya que no nos dice cómo debemos actuar en el futuro. Mejor dicho: la experiencia del significado no sirve para justificar del uso dado. Es decir, no sabríamos cómo distinguir la experiencia de significar suma y la de significar la cua-suma. Poseer un estado interno que nos indique qué función queremos decir mediante un signo no nos proporciona ningún tipo de apoyo que se sustente en un criterio normativo, esto es, no nos aclara cómo actuar en casos venideros. Ese estado interno no explica nuestra competencia.

La segunda objeción a los hechos irreductibles cuestiona su epistemología. Si no podemos distinguir dichos hechos irreductibles, es decir, conocer la diferencia entre el hecho irreductible de querer decir más y el otro hecho de querer decir cuás entonces, ¿cómo lo podemos conocer? El hecho irreductible de querer decir adición mediante "+" debería tener características únicas que nos permitan distinguirlo del hecho irreductible de querer decir la cuadición. Sin embargo, esto no sucede. No hay características fenomenológicas mediante las cuales podamos distinguir uno del otro y, luego, no 
podríamos conocerlo ni siquiera por introspección. Querer decir algo con una palabra no es algo que pueda reducirse, i.e., no es algo del tipo como tener una post-imagen amarillenta anaranjada. Tener una post-imagen, tener un dolor, etc., es algo que tiene cualidades fenoménicas únicas que son introspectables y, que, además, podemos conocer y distinguir. Supongamos que ese tipo de hechos irreductibles existiera y pudiéramos "verlo" por introspección, ¿cómo podríamos justificar epistémicamente las creencias del sujeto y con ello lo que quiere decir? Por si fuera poco, Wittgenstein niega de manera rotunda que la experiencia de querer decir algo con una palabra exista. Dicha propuesta de solución parece no dar en el clavo, ya que sigue sin responder al reto del escéptico.

La segunda objeción a los estados irreductibles se establece como sigue: tiene que ver con un conflicto entre el carácter normativo de estos estados y su carácter finito. El hecho de que alguien quiere decir algo con un signo tiene que ser finito, de lo contrario no podríamos captar el significado de dicha palabra. Si este estado involucrara pensar en los infinitos casos de aplicación de la adición, entonces no podríamos entender el significado al instante y, por lo tanto, no sabríamos de la correcta o incorrecta aplicación del concepto. Esos estados irreductibles tendrían que ser finitos, esto es, de algún modo tendrían que estar contenidos en nuestras mentes finitas. Dado un estado mental irreductible de (S1) de querer decir la adición mediante el signo “+", debe, de algún modo, contener de manera potencial todos los casos correctos en la aplicación que se haga del signo “+”. Es decir, tiene que ver con el carácter paradójico de la noción de experiencia del significado. Por un lado, tiene que ser finita para que la podamos captar e infinita para que pueda implicar infinitas normas del uso. 
Hasta el momento, hemos considerado distintas posibles soluciones que fallan en su intento por responder al reto escéptico.

Kripke, a través de la argumentación antes presentada, concluye que no hay hechos sobre la comprensión lingüística, es decir, que los intentos fallan, ya que no muestran que haya hechos que justifiquen y constituyan el querer decir algo mediante un signo, término y/o palabra. Por lo tanto, Kripke concluye que el querer decir algo con un signo tiene un carácter no fáctico. 


\section{Comprensión lingüística y realismo.}

\section{McGinn: Críticas a la paradoja escéptica y solución comunitarista}

En este capítulo abordaré las principales objeciones de McGinn en contra de Kripke, es decir, aquellas que aparecen en el célebre libro Wittgenstein on Meaning. An Interpretation and Evaluation. Las objeciones apuntan, principalmente, en dos direcciones: hacia lo que podemos llamar el escepticismo del significado y, en segundo lugar, a la solución escéptica y, por lo tanto, a la noción de comunidad.

La primera de las críticas radica en que Kripke, al querer interpretar a Wittgenstein, lo hace de una manera muy poco ligada al texto original. Lo que hace Kripke, como él mismo lo dice, es exponer el argumento escéptico derivado de su lectura de las Investigaciones Filosóficas. A diferencia de Kripke, McGinn trata de apegarse a lo que Wittgenstein en realidad dice. En otras palabras, lo que hace Kripke, según McGinn es mostrar, partiendo de un argumento filosóficamente relevante, algunos rasgos que podrían verse con cierta afinidad a los temas que trata el Wittgenstein de las Investigaciones y, según la opinión de McGinn, ni siquiera se ocupan de la misma problemática. En particular creo que la manera en que entienden el problema de seguir una regla es, en principio, distinta. Este capítulo versa sobre las críticas contra Kripke. 
En principio, podríamos decir que la estructura general del argumento wittgensteiniano según Kripke es la siguiente: Wittgenstein pone especial énfasis en la noción de normatividad, es decir, aquella noción que hace que apliquemos de manera correcta los signos de acuerdo al significado que atribuimos a ellos. Así, dicha noción es la que da pauta para los criterios de corrección lingüística. ${ }^{47}$

Por otro lado, hay que distinguir otro tipo de corrección que podemos llamar factual. ${ }^{48}$ La correspondencia con los hechos en el mundo es caracterizada estableciendo cómo es el mundo, i.e., qué proposiciones son correctamente aplicadas a los hechos. Es decir, una palabra, según el modelo del Tractatus, es usada de manera correcta si designa un objeto y sólo ese objeto en el mundo. En el primero de los casos, donde aparecen nociones normativas, se establece la corrección e incorreción de acuerdo con el significado determinado que tienen las palabras y/o signos. Entonces, podemos echar mano de la noción de uso correcto si y sólo si definimos que las palabras tienen determinado significado y no otro: $X$ significa $W$ y no $Z$.

Ahora bien, las nociones normativas (corrección e incorreción) y, por lo tanto, la noción de significado, también se ve amenazada desde la perspectiva kripkeana. Es decir, la paradoja pone en tela de juicio la relación entre significado y uso. Tal parece que no hay candidatos que constituyan el significado y a su vez satisfagan las exigencias normativas. ${ }^{49}$ Y esto se debe, principalmente, a que la noción de significado es normativa.

\footnotetext{
47 Me refiero a corrección semántica; entre la aplicación de una palabra/signo a cierto objeto, sensación y/o predicado. Es decir, la corrección/incorreción tiene que ver con la relación significado y uso.

${ }^{48}$ Factual correctness, i.e., stating a truth about the world.

${ }^{49}$ Recuérdese la paradoja (escéptica)
} 
Recordemos, pues, cómo va la paradoja escéptica planteada por Kripke. En primer lugar, consideremos el significado que solíamos darle a los signos en el pasado. Por cotidianidad asumimos que el uso que le damos al signo "+" en el presente concuerda con el uso que le dábamos en el pasado. Por ello, al tener nosotros que desarrollar la suma de, digamos, “67 +58" nos vemos inclinados a dar como respuesta "125". Sin embargo, nosotros hacemos estos cálculos basándonos en lo que sabemos que significa el signo "+". Es decir, asumimos de entrada que existe cierta estabilidad lingüística en usos pasados respecto al futuro que nos da cierto tipo de certeza para hacer los cálculos de manera confiada. Sin embargo, no es imposible pensar que el significado que ahora le damos a dicho signo haya cambiado. ${ }^{50}$

La estrategia de la que se echa mano en el desarrollo de la solución escéptica es intentar agotar aquellas posibles respuestas, a saber, un disposicionalismo simple, un disposicionalismo con cláusulas ceteris paribus, ${ }^{51}$ hechos irreducibles, etc. ${ }^{52}$ Es decir, según Kripke, lo que se desea es descalificar a todos los posibles candidatos que sean capaces de derribar la paradoja escéptica. A través de la argumentación kripkeana nos damos cuenta de que, en primer lugar, no hay candidatos que satisfagan los criterios normativos y con ello la constancia de significado. En segundo lugar, Kripke al haber descartado a todos los posibles candidatos nos dice, a modo de conclusión de la paradoja, que el querer decir algo

\footnotetext{
50 Es importante aclarar que no son los significados los que cambian, sino cómo sabemos, epistémicamente hablando que damos el mismo significado a los signos. Es decir, que los usamos en consonancia con el pasado.

${ }^{51}$ Es decir, un disposicionalismo con cláusulas de condiciones ideales.

52 Lo que intenta Kripke es mostrar mediante una estrategia de eliminación de posibles respuestas que ninguna de ellas es adecuada para responder de manera coherente a la paradoja escéptica, ya sea por no cumplir con los requisitos normativos, ya sea por el problema de la finitud, etc. Al haber descalificado todas las posibles respuestas él propondrá la suya, lo que comúnmente se ha llamado la solución comunitarista, la cual es capaz de dar cuenta tanto de la condición epistémica como de la metafísica.
} 
mediante un signo tiene un carácter no fáctico. Esto es, que no hay nada que constituya el significado.

McGinn describe la conclusión kripkeana como algo negativo con respecto al significado, esto es, creer que, si la paradoja que plantea Kripke es lo suficientemente robusta y bien articulada, entonces como coralario podríamos decir que la idea del significado colapsa. Sin embargo, la idea que tiene en mente McGinn es mostrar que sí hay hechos sobre la comprensión lingüística, es decir, existen hechos individuales. Esto es, McGinn defenderá una postura realista con respecto a los hechos sobre la comprensión lingüística, i.e., sí hay hechos con respecto a lo que queremos decir con nuestras palabras.

La estrategia que aparece en Wittgenstein On Meaning de la que nos ocuparemos en este capítulo será positiva, es decir, intentar mostrar que las presuposiciones acerca de las adscripciones del significado que tiene el escéptico kripkeano son falsas. McGinn intentará mostrar una falla en la propia argumentación de Kripke, ya que éste nos pide que citemos un hecho que justifique y a la vez constituya la noción de significado. Desde el principio de la argumentación kripkeana, no hay algo, un hecho, que justifique lo que se quiere decir mediante un signo. En palabras de McGinn, Kripke argumenta contra un hombre de paja, por lo cual tiene ganada la discusión desde un principio. Esto es, la asunción que tiene en mente el escéptico es que para que una oración sea, o bien, verdadera o falsa, ésta tiene que mostrar el hecho en el mundo que la torna verdadera o falsa. Sin embargo, lo que uno quiere decir mediante un signo o una palabra no establece relación alguna con el mundo, p.ej., el discurso donde aparece el signo de la adición no establece una figura en el mundo, i.e., no hay un hecho que torne verdadera o falsa dicha proposición. Es decir, la 
paradoja se respondería si le mostrásemos un hecho que hace verdadero lo que se quiere decir mediante una palabra. Esto es, hay un hecho que hace verdadera la siguiente oración: "Osvaldo quiere decir rojo mediante 'rojo'". Si descartamos la idea de que las adscripciones de significado tienen su contraparte en el mundo como hechos, entonces podemos pensar en aquellas mediante sus condiciones de aseverabilidad y mediante el rol del discurso donde forman parte. Ahora bien, no creo que lo que McGinn dice sea correcto, es falso que el escéptico hipotético de Kripke presupone aquello que quiere demostrar. El experimento kripkeano dice, suponiendo que haya hechos sobre el significado, ¿cuál es el que puede ser citado para detener al escéptico?

Por otro lado, la estrategia que emprende en Wittgenstein: On Rules and Private Language, no es exclusiva de este terreno. McGinn nos propone que comparemos tres modelos que pueden verse en paralelo a la estructura que plantea la paradoja escéptica. Por ejemplo:

a) Las éticas no cognitivistas que postulan que no hay hechos que tornen verdaderas o falsas las proposiciones que versan sobre la ética. Este tipo de discurso no incluye proposiciones de tipo factual $y$, de este modo, no puede la ética no cognitivista encontrar hechos adecuados que correspondan a las proposiciones éticas. Sin embargo, no por eso diríamos que dichas proferencias carecen de significado. En vez de abandonar las cuestiones que versan sobre la ética como vacías (carentes de significado), el no cognitivista da otra noción de significado para dichas proposiciones. El emotivismo podría ser visto en paralelo a la solución escéptica, i.e., los juicios de valor no afirman nada sobre los objetos externos, 
estos sólo expresan ciertas emociones. Por lo tanto, estos juicios de valor no son ni verdaderos ni falsos. No obstante, no se sigue que ellos carezcan de sentido. Lo que es un sinsentido sería hablar de verdades morales y/o de que esos juicios tengan valor de verdad.

b) El instrumentalismo postula, a grandes rasgos, que las teorías y los modelos científicos no deben o pretenden representar la realidad. Más bien apuntan a que las teorías científicas no son sino herramientas. Es decir, según ellos, no hay correspondencia entre los hechos del mundo y los enunciados teóricos. Sin embargo, no por ello son desechados, sino que sirven como métodos para interpretar los hechos reales. El instrumentalismo en vez de pensar aquel discurso sobre los inobservables como carente de significado, da en su lugar otro modo de hablar de ellos y con ello les da otro significado distinto desde una perspectiva organizacional y mediante condiciones de aseverabilidad.

c) El platonismo que afirma que los objetos matemáticos son entes abstractos y que, por lo tanto, una afirmación matemática no es capaz de encontrar un modo de verificación mediante un modelo de contrastación con la realidad. Esto es, a pesar de que no haya modo de verificación, no vemos a las matemáticas como carentes de significado. Y, a su vez, decimos que las matemáticas obtienen su significado a través de su aplicación empírica. Esto puede verse, de nuevo, como una solución a la paradoja escéptica, i.e., se le concede al escéptico que no hay hechos matemáticos, sin embargo, no se concede que las matemáticas carezcan de sentido. Así lo podemos observar en el libro Science without Numbers de Field: 
"no es necesario considerar que los enunciados matemáticos poseen condiciones de verdad genuinas y por eso no se requieren hechos 'raros' que correspondan a ellos". 53

Estos tres breves ejemplos sirven para dar cuenta de cómo y de qué manera corre la dialéctica que Kripke le atribuye al filósofo vienés. Esto es, según McGinn, existe en a), b) y c) una paradoja escéptica y hay un modo de salir de ahí, no recurriendo a una solución escéptica como Kripke. Es decir, McGinn piensa que hay una solución directa al problema.

Sin embargo, hay algunas objeciones con respecto a los ejemplos que da McGinn. En primer lugar, en a) hay un cierto sentido donde las afirmaciones morales podrían sí tener condiciones de verdad y podría haber hechos que hagan verdaderas a sus afirmaciones. Por ejemplo, tenemos la oración 'es malo mentir'. Uno podría negar que hay un hecho que haga que mentir sea considerado como malo. Sin embargo, podríamos pensar que dicha oración quiere decir algo como 'mentir no me gusta o me causa angustia', entonces sí habría un hecho que haría que la oración 'es malo mentir' sea verdadera, a saber, que sucedan tales y cuales sensaciones fisiológicas en mi. En b) podríamos imaginar algo más o menos del mismo tipo, podríamos imaginar el discurso sobre los inobservables de manera fáctica, sólo que los hechos no serían los que regularmente se piensan, sino hechos sobre los beneficios y la utilidad práctica que puede tener hablar sobre dichas entidades inobservables. Por

53 "[...] Mathematical sentences need not to be regarded as possesing genuine truth conditions and so do not call for 'queer' facts to correspond to them". Podríamos pensar que los enunciados matemáticos verdaderos sí corresponderían a relaciones entre objetos abstractos. 
ejemplo, decimos 'el electrón tiene tal y cual propiedad' podríamos pensar que lo que hace verdadera dicha oración es el hecho de que la realidad está formado por ellos y éstos tienen tal y cual cualidad. Es decir, lo que haría verdadero dicha oración son los hechos sobre la utilidad práctica. Por lo tanto, podríamos decir que los ejemplos de a) y b) no son afortunados, pues no se ve la analogía entre dicha paradoja escéptica y los ejemplos dados.

\section{1}

\section{Esbozo y crítica de la solución escéptica (Kripke)}

En esta parte me ocuparé de indagar si es correcto asumir que Wittgenstein comparte con Kripke que la noción de seguir una regla y la noción de comunidad van de la mano. En otras palabras, si es legítimo decir que el seguir una regla obtiene su certidumbre mediante miembros que participan dentro de una comunidad.

La comunidad es introducida mediante la noción de normatividad que se asocia al lenguaje. Decimos de una persona que usa una palabra de manera incorrecta si no concuerda con el uso de los otros miembros de su comunidad lingüística y, por el contrario, decimos que usa una palabra de manera correcta si concuerda con ellos. Mejor dicho, si no usa una palabra de acuerdo con las normas comunitarias, entonces podríamos decir que no significan nada. Es decir, la noción de normatividad se encuentra relativizada a una comunidad.

Sin embargo, ¿qué sucede con individuos aislados? En este caso, lo más que podríamos decir es que parece que usan las palabras de manera correcta. De este modo, podemos ver 
que la noción de seguir una regla adquiere sentido sólo si es concebida con otros seguidores de reglas. Esto es parte medular de la solución escéptica aducida por Kripke:

Entonces la noción de seguir una regla resulta ser una noción social que, de algún modo, es similar a la manera en que ser un conformista o un miembro de un club social o una persona que viste a la moda son nociones sociales: ninguna de estas propiedades puede ser parte de un individuo en aislamiento. ${ }^{54}$

Tal como la presenta Kripke dicha solución consiste en reemplazar las condiciones de verdad (correspondencia con los hechos) por condiciones de aseverabilidad y, con ello, introducir la comunidad a la noción de seguir una regla. Es decir, las condiciones de aseverabilidad y adscribir significado involucran esencialmente la noción de comunidad. Por lo tanto, decir que alguien quiso decir adición mediante “+" está garantizado sólo si:

1) Si desde la perspectiva de un miembro de la comunidad sus respuestas que involucran el uso de ' + ' concuerdan con las respuestas de una comunidad que usa ' + '.

2) Si él puede confiar en las interacciones, donde hay criterios de concordancia y formas de vida, con los demás miembros de la comunidad que involucran su uso de ' + '.

Por ello, la noción de regla parece ser esencialmente social. Y, por lo tanto, se sigue que no

\footnotetext{
54 "Thus the notion of rule-following turns out to be a social notion in somewhat the notions of a conformist or a social club member or a fashionable dresser are social notions: none of these properties can be possessed by individuals consider in isolation". (1984: 78)
} 
podemos dar cuenta de la noción de seguir una regla desde una perspectiva individualista. ${ }^{55}$ Si consideramos a un individuo aislado, según Kripke, todo lo que podemos decir es que parece que usa las palabras de manera correcta; sin embargo, no podemos asegurar que realmente use las palabras de manera correcta. Es decir, según Kripke, desde la perspectiva de primera persona no es posible distinguir si un individuo sigue o no de manera correcta una regla, tan sólo podríamos decir que sigue sus inclinaciones. Por lo tanto, la noción de seguir una regla no puede ser concebida de manera individualista, sino que requiere de manera necesaria otros "seguidores de reglas". ${ }^{56}$ La disputa radica en mostrar si una regla puede dar criterios objetivos, ya sea desde la perspectiva de primera (McGinn) o de tercera persona (Kripke).

Nos dice McGinn, seguir una regla no depende de una perspectiva de tercera persona, es decir, éste no cree que para determinar si una regla se sigue de manera correcta deban existir observadores que puedan refrendar que se hizo de manera correcta. Además, McGinn considera que la existencia de las reglas depende de un uso regular; cuando Wittgenstein utiliza "costumbre", "práctica" lo hace para sugerir la idea de multiplicidad, sin embargo, es una multiplicidad que está ligada a instancias de seguir una regla y no de personas que siguen reglas.

La regularidad, es decir, la tesis de la aplicabilidad múltiple de las reglas puede ser

\footnotetext{
${ }^{55}$ Al parecer McGinn utiliza "individualista" en el sentido que lo hace Tyler Burge en su artículo Individualism and the Mental. (1979). Podríamos parafrasearlo del siguiente modo: Una propiedad de una persona es individualista sólo si la instanciación de dicha propiedad puede ser explicada sin hacer referencia a alguna otra persona. Una propiedad es social en caso contrario.

${ }^{56}$ Pienso que Kripke podría decir que no tiene sentido cuestionarse sobre si es posible que un individuo aislado siga reglas.
} 
vista de dos maneras; una débil y una fuerte:

\section{Versión débil:}

1. Para cada regla $\beta, \beta$ debe ser repetidamente aplicada sobre varios individuos y en tiempos diferentes.

Versión fuerte:

2. Para cada regla $\beta, \beta$ deber ser repetidamente aplicada por un solo individuo. ${ }^{57}$

Y, según McGinn, de ahí proviene el dictum wittgensteiniano "el significado es el uso": un signo tiene significado sólo en virtud de ser (constantemente) usado en un cierto sentido, por lo cual no es imposible pensar que el significado sea posible en aislamiento. Imaginemos el caso de un individuo aislado que usa con cierto y determinado significado la palabra 'conejo' siempre que ve un conejo. Dicha palabra, al ser usada de manera constante y con el mismo sentido, adopta el significado de lo que nosotros llamamos conejo. Sin embargo, parece que la explicación de McGinn es circular, pues intenta explicar el significado que damos a las palabras echando mano de cómo usa un individuo sus palabras. Creo yo que Kripke tiene razón en mostrar que la perspectiva de tercera persona ofrece mejores criterios para fijar los significados. Es decir, nuestro sujeto no la usa para referirse al alimento del conejo, ni a alguna extremidad del conejo, ni solamente al pelo del mismo conejo. Cada que nuestro sujeto ve un conejo, él grita 'conejo'. La instanciación de la regla

\footnotetext{
${ }^{57}$ De acuerdo con McGinn, no es claro si cada individuo que capta una regla debe seguirla varias veces o si las aplicaciones de dicha regla pueden ser distribuidas sobre varios individuos. $(P, Q$ y $R$ siguen la regla $\beta)$ o $(P$ sigue $\beta$ de manera constante).
} 
se da a través del tiempo en que nuestro sujeto al ver conejos distintos (o el mismo) cada día dice 'conejo'. Si $a^{1}, a^{2}, a^{3}, a^{4}, \ldots . . . a^{n}$ tienen las cualidades fenomenológicas suficientes de un conejo, él le llamará 'conejo' y, según McGinn, sería un criterio válido decir que él ha dado las pautas de lo que para él es un conejo y que lo llama por el nombre 'conejo'. Sin embargo, la explicación de McGinn no parece ofrecer más que la posición disposicionalista.

Kripke llega a la conclusión de que una regla necesita a fortiori un observador externo que sirva de criterio para justificar su uso, es decir, la regla a seguir obtiene su objetividad mediante la perspectiva de tercera persona. No obstante, McGinn cree que eso se debe a una confusión que viene de las nociones 'privado' y 'social'. Kripke piensa en estas dos nociones como si fueran los contrastes, es decir, como antónimos. Sin embargo, en Wittgenstein On Meaning, McGinn asegura que lo opuesto a 'privado' debe ser 'público' o 'explícito' ${ }^{58}$

Respecto a cómo interpreta Kripke la noción concebida de lo privado, el comportamiento público de una persona, por ejemplo, al seguir una señalización, se considerará como "privado", al menos si se describe de forma individualista; y así de alguna manera podríamos propiamente afirmar que todo comportamiento que no se rige por reglas (e.g. el dolor) puede tomar lugar, y de hecho lo hace, "de forma privada", pues describirlo no requiere hacer referencia a otras personas. Por eso es posible agitar el brazo [como cuando uno saluda a alguien] "de forma privada", pero no es posible seguir la regla de adición "de forma privada" ... Aquello que es público puede ser "privado" en este sentido - por lo tanto, que algo sea cognoscible para otros no es suficiente para argumentar la no privacidad. ${ }^{59}$

\footnotetext{
58 Public or overt.

59 “On Kripke's understanding of the intended notion of privacy a person's overt behavior, say in following a sign-post, is to be considered 'private', at least if it is described individualistically; and so we could quite
} 
Cuando aplicamos una palabra a un cierto objeto, no lo hacemos creyendo que esa aplicación esté basada en razones, es decir, no actuamos sobre la base de razones para dar por justificada nuestra aplicación. Principalmente a lo que se opone Wittgenstein es a la epistemología tradicional: que las nociones de duda y razón sean correlativas; no debemos pensar que no tenemos dudas sólo si tenemos buenas razones.

"Todos los pasos ya están realmente dados" quiere decir: ya no tengo elección. La regla, una vez estampada con cierto significado, traza las líneas de su prosecución a través de todo el espacio. Pero si algo así fuese realmente el caso, ¿de qué me valdría?

No; mi descripción sólo tenía sentido si se entendía simbólicamente. Así es como me parece, debí decir. Cuando elijo la regla, no elijo. Sigo la regla ciegamente". 60

Lo que Wittgenstein pretende mostrar es que seguimos reglas de manera habitual y no siempre lo hacemos guiándonos por razones, es decir, pretende eliminar aquellas

properly claim that all non-rule governed behavior (e.g. pain behavior) can and does take place 'privately', since its description does not require reference to other people. It is thus possible to wave your arm 'privately' but not possible to follow the addition rule 'privately'... What is public can be 'private' in this sense knowability by others is therefore not sufficient for non-privacy". (1984: 79)

60 "All the steps are already taken" means: I no longer have any choice. The rule, once stamped with a particular meaning, traces the lines along which it is to be followed throught the whole of space. But if something of this sort really were the case, how would it help?

No; my description only made sense if it was to be understood symbolically. I should have said: This is how strikes me. When I obey a rule, I do not choose. I obey the rule blindly. (PI, §219) 
caracterizaciones intelectuales racionalizadoras. Simplemente así actúo, tal es la manera en que lo hago. Si se optara por justificar mediante las razones, éstas deben tener un fin en algún punto. "La cadena de razones tiene un fin" .61

La tesis que afirma que usar un signo en concordancia con cierta regla no está fundado en razones no muestra de ningún modo que pretenda suscribir algún tipo de escepticismo, simplemente quiere mostrar que del hecho de que una regla se siga a ciegas no quiere decir que no haya conocimiento ni certeza de lo que queremos decir cuando aplicamos una palabra a cierto objeto. “[...] usar una palabra sin justificación no quiere decir usarla injustamente". 62

Del hecho de que yo no pueda probar al escéptico kripkeano que mi uso actual del signo "+" es correcto, no se sigue que yo no sepa cómo he de aplicarlo de manera correcta o que no tengo derecho de aplicarlo como yo me vea inclinado a hacerlo. Por ello, concluye McGinn que no es plausible pensar que Wittgenstein sostenga un argumento escéptico tal como lo piensa Kripke. Las observaciones que aparecen en las Investigaciones dan muestra de que Wittgenstein no da razones para sostener un escepticismo, ya sea de índole constitutivo y mucho menos uno epistemológico.

A lo largo de la exposición de Kripke podemos observar cómo se van descartando aquellos candidatos que resultan no estar en consonancia con una posible respuesta al reto escéptico esgrimido en Wittgenstein: On Rules and Private Language. Uno de los candidatos

\footnotetext{
${ }^{61}(\mathrm{PI}, \S 326)$

${ }^{62}$ (PI, §289)
} 
que mayor atención han recibido son las disposiciones. ${ }^{63}$ En particular, las principales objeciones a las disposiciones es que son finitas, ${ }^{64}$ el problema del error $y$, en tercer lugar, no ofrecen una respuesta a la cuestión normativa. Las disposiciones describen cómo actuamos y no prescriben cómo hemos de actuar en función de concordar con nuestros usos.

\section{2}

\section{La estrategia realista de McGinn vs el antirrealismo de Kripke}

La estrategia de McGinn para mostrar que Kripke ha fallado es la siguiente: mostrar que los candidatos que Kripke ha descartado como posibles respuestas no agotan las posibilidades, es decir, la conclusión que saca no es convincente, ya que no contempló todas las posibles respuestas. En particular, McGinn defenderá que la noción de capacidad es lo suficientemente robusta para socavar el reto escéptico.

\footnotetext{
${ }^{63}$ Un ejemplo de ello son las disposiciones complejas de Soames. Veáse Facts, Truth Conditions and the Skeptical Solution to the Rule Following Paradox (1998) y Skepticism about meaning: Indeterminacy, Normativity and the Rule Following Paradox (1997).

${ }^{64} \mathrm{El}$ problema de la finitud radica en que nuestras mentes finitas podrían no ser capaces de dar reglas que se aplican a una infinidad de casos
} 


\subsubsection{El argumento escéptico y la extensión a las categorías semánticas}

Recordemos que en Wittgenstein. On Rules and Private Language, Kripke da cuenta de la paradoja partiendo de los ejemplos que son propios de la aritmética y después lo hace extensivo hacia las nociones de sensaciones y predicados sobre objetos materiales. La propuesta de McGinn es que aquella paradoja puede y debe ser extendida a todas las posibles categorías semánticas, ${ }^{65}$ esto debido a que si Kripke quiere concluir que la noción de significado se desvanece, entonces, debe ser capaz de pasar el test y mostrar que si la paradoja es correcta, entonces todas las palabras carecen de significado y no sólo las que atañen a las funciones aritméticas.

Considérese la siguiente extensión aplicado al término singular 'Kripke'. He usado dicho nombre un número finito de veces, sin embargo, consideramos que podríamos utilizar dicho nombre en otras circunstancias o en otro tiempo, p.ej., si veo a Kripke en una conferencia titulada 'Colors, Sounds, Numbers, Names, Inferences, Minds' a celebrarse en el Instituto de Investigaciones Filosóficas el día de mañana.

No obstante, tenemos la hipótesis escéptica que cuestiona nuestro derecho a aplicar 'Kripke' a Kripke en un tiempo futuro; dicho escéptico dice que el uso correcto de 'Kripke' tal como lo determina mi entendimiento pasado es aplicarlo a Putnam después de algún tiempo futuro $t$. De este modo, la hipótesis escéptica sostiene que 'Kripke' se refiere a Kripnam, donde Kripnam es o bien Kripke si es visto antes de $t$ o bien Putnam si es visto después de $t$.

\footnotetext{
${ }^{65}$ Puede ser extendido a nombres propios y a conectivas lógicas
} 
Consideremos la siguiente extensión a las conectivas lógicas, en particular a la de la conjunción ' $y$ '. Asumo que ' $y$ ' se refiere a la función de la conjunción, como lo define su tabla de verdad dada para cualesquiera argumentos arbitrarios. Por lo tanto, asumo que, si tengo cualesquiera dos oraciones unidas mediante la conjunción ' $y$ ', ésta será verdadera sólo en caso de que ambas oraciones también lo sean. Sin embargo, la hipótesis escéptica que correría sería más o menos lo siguiente: él me pide que presente un hecho que justifique que con ' $y$ ' no quise decir 'cua-y', donde su tabla de verdad concuerda con la de la conjunción sólo con respecto a oraciones de menos a cien palabras y a partir de ciento uno concuerda con la tabla de la disyunción.

A pesar de la extravagancia, no parece ser que las hipótesis escépticas sean, en principio, imposibles. Pero, ¿qué podemos responder para refutar al escéptico? El uso que hacíamos en el pasado del nombre 'Kripke' o el uso que hacíamos de la conectiva 'y' no son suficientes, así como tampoco lo son los estados irreducibles, etc., pues éstos son compatibles con la hipótesis escéptica.

Por lo tanto, McGinn sostiene que dicha paradoja puede generalizarse a cualquier tipo de palabra. Es relativamente sencillo imaginar escenarios que muestren que dicha paradoja es aplicable a adjetivos, demostrativos, adverbios, etc. ${ }^{66}$

\footnotetext{
${ }^{66}$ Hasta aquí están de acuerdo McGinn y Kripke. Más adelante se verá cuál es la extensión que piensa McGinn que debe hacerse para que la paradoja se sostenga.
} 


\subsubsection{El argumento escéptico y la noción de referir}

En segundo lugar, Kripke plantea su paradoja en términos del significar, pero apunta McGinn que nada se pierde si se sustituye la noción de significar por la de referir. Es decir, el problema antaño de ' + ' puede ser reformulado como una pregunta sobre lo que constituye mi referir a la adición y no a la cuadición. Por lo tanto, si mi uso es correcto o incorrecto dependerá de cuál era la referencia de ' + ' en el pasado. En el caso de los nombres propios la relación entre el nombre y su referencia parece ser más clara. ¿Qué hecho constituye mi referir con 'Kripke' a Kripke y no a Putnam?

La referencia, dice McGinn, así como el significado, tienen el requisito que se exige de normatividad, ya que para Kripke, la normatividad que se asocia al lenguaje es una cuestión de usar una palabra en concordancia con el significado con la que fue utilizada en el pasado. 


\subsubsection{El argumento escéptico y la extensión a la noción de conceptos ${ }^{67}$}

McGinn identifica una carencia en el argumento expuesto por Kripke. Dicha carencia radica en que la paradoja escéptica debe, si se quiere que sea lo suficientemente relevante, extenderse a la noción de pensamiento y no sólo ser aplicable a la noción de significar. Esto es, debe mostrar que la noción de poseer tal o cual concepto es factualmente vacío como lo es para la noción de significar. Recordemos que ésta es la conclusión que arroja la paradoja, no hay hecho alguno que constituya lo que queremos decir mediante un signo.

Así, pues, dice McGinn:

Es necesario para Kripke aplicar la tesis anti - factualista a conceptos y pensamientos por (al menos) dos razones. Una es que la paradoja sería de relativo poco interés si no tuviera implicaciones para la posesión de conceptos: pues si la idea de que a las adscripciones de conceptos a la gente les corresponden hechos en el mundo estuviera en buena forma, entonces no habría una amenaza general a nuestra creencia de que nuestras mentes pueden albergar representaciones de estados de cosas extra-mentales determinados- la noción general de intensionalidad no estaría bajo amenaza... ${ }^{68}$

Y agrega que:

\footnotetext{
${ }^{67}$ La paradoja del argumento debe ser extendida a la noción de 'concepto' i.e., pensamiento. Esto con el fin de que la paradoja resulte mejor posicionada ante alguna refutación.

68 "It is necessary for Kripke to apply the anti-factualist thesis to concepts and thoughts for (at least) two reasons. One is that the paradox would be of relatively little interest if it had no implications for concept possession: for the idea that ascriptions of concepts to people correspond to facts-in-the-world were in good order, then there would be no general threat to our belief that our minds can house determinate representations of extra-mental states of affaires - the general notion of intentionality would not be under threat...". (1984: 144)
} 
La segunda razón se sigue inmediatamente de la primera razón: si la factualidad y determinación de los conceptos no estuviera bajo amenaza a partir de la paradoja, entonces parecería que tenemos una respuesta fácil al escéptico semántico de Kripke, a saber que ' + ' significa adición en mi lenguaje, simplemente porque yo asocio ' + ' con el concepto de adición (y no cuadición): esto es, cuando yo uso ' + ' en oraciones, el pensamiento que tengo y que comunico es un pensamiento cuyo contenido contiene el concepto de adición. ${ }^{69}$

En este último caso, de modo nada conveniente para Kripke, la factualidad de los conceptos podría ser usada para establecer la factualidad del significado y el hecho constitutivo en los conceptos cuando utilizo determinada palabra; el significado sería el concepto expresado. Si los hechos de lo que quiere decir nuestro sujeto, John, pudieran reducirse a los hechos (contenido) de los pensamientos en conjunto con los usos que John hace del signo ' + ', entonces tendríamos un conjunto de hechos que refutaría al reto escéptico. Es decir, el contenido de las actitudes proposicionales que tiene John al usar el signo '+' podría servir para determinar qué quiso decir cuando emplea ' + '. Esto es, él podría mirar qué pensamiento ocurre cuando utiliza un signo y, por lo tanto, sabría qué quiso decir con dicho signo.

\footnotetext{
69 "The second reason follows immediately upon the first reason: if the factuality and determinacy of concepts were not under threat from the paradox, then it would seem that we have a ready reply to Kripke's semantic sceptic, namely that "+" means addition in my language simply because I associate with "+" the concept of addition (and not quaddition): that is, when I use " + " in sentences the thought I have and communicate is a thought whose content contains the concept of addition". (1984:145)
} 


\section{3}

\section{McGinn y la solución realista a la paradoja escéptica}

Por último, la solución de McGinn, a diferencia de la solución comunitarista de Kripke, es una solución directa; y corre en tres partes. La primera considera la teoría causal de la referencia, esto es, si la relación de referencia se establece entre un nombre y un objeto, entonces hay una consecuencia normativa; la aplicación correcta de un nombre se satisface sólo si se usa para dicho objeto.

Hemos acordado, siguiendo a Kripke, que la relación de referencia no puede haber sido obtenida por la aplicación actual del nombre, ni por los estados mentales, ni por disposiciones lingüísticas. Sin embargo, nos dice McGinn; ¿por qué no echar mano de Naming and Necessity? Es decir, utilizar el método de la teoría causal de la referencia para establecer qué uso es correcto con respecto a los nombres utilizados. Por ejemplo, recordemos que parte de la extensión de la hipótesis escéptica consistía en que 'Kripke’ se refiere a Kripnam, donde Kripnam es o bien Kripke si es visto antes de $t$ o bien Putnam si es visto después de $t$. Si se acepta la propuesta de McGinn de utilizar la teoría causal de la referencia, podríamos fijar la referencia del nombre 'Kripke' sin mayor problema. Pues se excluye la confusión de si queremos referir a Putnam o si nos referimos a Kripke, ya que en el origen de la cadena causal estaría Kripke por el nombre 'Kripke'. De manera similar podríamos pensar que mi uso actual de 'caballo' tiene muestras de caballos en el origen de la cadena causal y no a tigres, por lo tanto, la hipótesis escéptica sería refutada, ya que el escéptico no podría decir que después de un tiempo $t$ llamámos 'tigres' a los caballos. Por 
lo tanto, echar mano de la teoría causal de la referencia nos ofrece una respuesta a la pregunta constitutiva del reto, ya que cumple con el requisito normativo y nos señala cuál es el hecho mediante el cual nos referimos a un objeto mediante un nombre. ${ }^{70}$ La cuestión fallida con este tipo de solución sería que en primer lugar la paradoja se aplica a todo tipo de palabra y en segundo lugar, McGinn tendría que probar que la referencia es normativa. Del hecho que el significado sea normativo no se sigue que la referencia también lo sea.

La segunda parte, echa mano del programa griceano que establece que los hechos semánticos deben ser explicados en términos de las actitudes proposicionales que aparecen en la comunicación. Es decir, los hechos del lenguaje deben ser reducidos a hechos psicológicos y explicados en términos de éstos: p.ej., "creo que", "tengo la intención de..." Es decir, el significado sería explicado en términos totalmente distintos. Por lo tanto, la respuesta griceana al reto sería explicada del siguiente modo: querer decir ayer, hoy o mañana adición mediante el signo ' + ' es proferir oraciones que contengan ' + ' con la intención de que una audiencia crea y se vea envuelta en el proceso de querer adición mediante el signo ' + '. Dicha herramienta griceana sirve sólo presuponiendo que la posesión de conceptos es uniforme dentro de una comunidad. A pesar de que esta empresa podría resultar provechosa, McGinn evade uno de las principales postulados del reto, a saber, que la paradoja se aplica a todo el lenguaje significativo, estados de comprensión e intenciones

\footnotetext{
70 McGinn ofrece dos afirmaciones que responden a la pregunta de por qué Kripke no tomó en cuenta su propia teoría como una respuesta al escéptico. La primera de ellas es que en principio el reto se da en términos de significado y no de referencia. En segundo lugar, se ocupa de ejemplos matemáticos, donde el problema de la referencia es bastante visible.
} 
lingüísticas.

La tercera posibilidad a la que apela es a la idea de que poseer un concepto es poseer una capacidad. ${ }^{71}$ Es decir, los escritos de Wittgenstein muestran que poseer un concepto es similar a tener cierta capacidad, donde las capacidades pueden ser entendidas como técnicas. Quizá Kripke, como muchos otros, no puso especial atención en las capacidades, ya que eran vistas como disposiciones y, por lo tanto, con las objeciones hacia el disposicionalismo bastaba. Sin embargo, McGinn no las caracteriza del mismo modo. Es decir, el hecho de identificar conceptos con capacidades sucede de manera distinta dependiendo el tipo de concepto y el tipo de capacidad. Las capacidades más fáciles de explicar son aquellas que podríamos llamar observacionales. Poseer el concepto "verde" es tener la capacidad de discriminar, reconocer, identificar los objetos verdes. Cuando enseñamos a un niño el concepto "verde", nosotros esperamos que el aprendiz sea capaz de discriminar, reconocer e identificar las cosas verdes. Dicho reconocimiento puede hacerse mediante el uso de palabras o sin ellas. Según McGinn, la capacidad de reconocer cosas rojas es distinta a la capacidad, por decir algo, de reconocer cosas qua-rojas, ya que las capacidades involucran pensamientos que distinguen los conceptos. Esto es, para McGinn, cuando se hacen cómputos con el signo ' + ' se involucra la capacidad de la adición y no de la cuadición, porque la capacidad que está en juego es la de sumar y no la de la cuasuma.

\footnotetext{
71 “Capacidad” no quiere decir "disposición”, ya que, si fuera así, las objeciones correrían tal y como fueron planteadas para este tipo de análisis.
} 
Por último, recordemos que cualquier respuesta al reto escéptico, según Kripke, debería de ser capaz de responder tanto la parte constitutiva como la parte epistémica. De este modo, McGinn piensa que la noción de capacidad puede responder la parte constitutiva del reto y que una perspectiva de primera persona responde la cuestión epistémica.

Veamos la primera parte. McGinn sugiere que oraciones del tipo "' + ' significa adición en el idiolecto de S" o “"+' significa adición en mi idiolecto" si son verdaderas, lo son en virtud de un hecho semántico, a saber, el hecho de que el hablante usa '+' para referirse a la función aritmética de la adición. La propuesta realista nos ofrece entender la noción de hechos de comprensión lingüística en términos de capacidades o habilidades, como he dicho, no deben confundirse con las disposiciones antes objetadas. Sin embargo, McGinn no esclarece la noción de capacidad más allá de lo antes expuesto. Esto es, decir la capacidad de tener el dominio de un concepto observacional es tener la capacidad de reconocer, por decir algo, cosas verdes, pero ésta explicación parece ser burda. Podría haber condiciones de poca o mala iluminación. Regularmente, pensaríamos que poseer un concepto implica muchas más cosas que sólo el hecho de reconocer y discriminar. Por ejemplo, de alguien que sabe cómo sumar esperamos más que el simple hecho de que reconozca que una palabra expresa la suma de dos números. También podríamos pensar que para poder poseer conceptos como protón o quark no basta con la mera capacidad de reconocer. Por otro lado, McGinn identifica la posesión de conceptos con una capacidad infinita. Esto es, si decimos que alguien posee el concepto 'verde', entonces, según el 
realista, tendría que haber una capacidad de reconocer todas las cosas verdes. Sin embargo, esto nos parecería extraño. Recuérdese el carácter paradójico de los hechos irreducibles. Si McGinn puediera ofrecer una caracterización no circular de capacidad y nos dijera en qué se diferencian de las disposiciones, quizá podría tener alguna posibilidad en contra del escéptico. Recordemos que el escéptico está pidiendo una explicación constitutiva normativa entre comprensión y uso. Sin embargo, la propuesta de McGinn parece eludir el problema de la normatividad, pues las capacidades, así como son entendidas no explican la corrección de uso lingüístico. Por otro lado, McGinn menciona que poseer la capacidad de sumar significa estar en un estado mental irreducible, cuyo contenido es el ser capaz de sumar. Pero, como mencionamos antes, la objeción en contra de los hechos irreducibles es que no podríamos diferenciar la fenomenología del estado mental de querer decir la cuadición y la adición. Al parecer, los argumentos de McGinn no sirven para derribar la postura escéptica y, por lo tanto, tampoco satisface la condición constitutiva del reto. La condición epistémica, hemos visto, busca la justificación de lo que queremos decir con nuestras palabras. Este problema ha de verse desde dos perspectivas, a saber, la de primera y tercera persona. Algunos filósofos, encabezados por Descartes, han sugerido que el conocimiento de primera persona es infalible, es decir, captamos nuestros estados mentales por medio de la introspección y tenemos autoridad sobre ellos. En cambio, la perspectiva de tercera persona no puede echar mano de la introspección, sino que se basa en la evidencia disponible sobre el comportamiento y lo que hablante dice, por ello puede ser falible. McGinn arguye que es imposible derribar la condición epistémica haciendo uso de las explicaciones de tercera persona. La manera en que S justifica la 
capacidad de sumar con el signo "+" son los usos reales que hace $\mathrm{S}$ al usar el signo "+". Sin embargo, los usos reales están subdeterminados por la comprensión, es decir, usos distintos también estarían apoyados por la evidencia disponible.

Sin embargo, McGinn considera que la única salida viable para derrotar al escéptico es tomar partido por la perspectiva de la primera persona. Es decir, el hablante puede hacer uso de sus mecanismos introspectivos y hallar qué capacidades son las que asocia con tal concepto y los usos pasados serían inferidos a partir de la introspección de sus recuerdos. Sin embargo, se podrían objetar dos cuestiones. La primera con respecto a falibilidad de su memoria y la segunda ataca a la imposibilidad de distinguir entre la fenomenología de dichos estados de comprensión lingüística. No podríamos haciendo uso de la introspección distinguir entre querer decir la suma o la cuasuma. De este modo, estar en determinado estado mental de comprensión o tener la capacidad lingüística de querer decir tal o cual sigue sin tener justificación. Por lo tanto, McGinn no satisface ninguna de las dos condiciones del reto. 


\section{Solución al reto escéptico}

El reto escéptico queda, si buscamos un hecho que constituya nuestro querer decir algo mediante un signo, sin respuesta. Sin embargo, Kripke no intenta mostrar que nuestro lenguaje carezca de significado y conclusiones extrañas de este tipo, sino que busca argüir que no hay hechos que justifiquen lo que queremos decir mediante un signo. Si existe algo que justifique y regule nuestro uso de los términos, es algo que no está dentro de nosotros. Mi estado mental tal y como lo tengo en el presente no me dice cómo debemos actuar en el futuro. A pesar de tener una fuerte inclinación a pensar que hay algo en mi mente que me indica cómo proceder en casos posteriores, en realidad, no es más que una mera tentación.

El reto que plantea Kripke, siguiendo a Wittgenstein, puede verse como una nueva forma radical de escepticismo - al igual que Hume, Kripke nos plantea un escenario donde lo que se cuestiona es aquel nexo que une pasado, presente y futuro-. La noción de significado es la que debe establecer el nexo entre usos pasados, presentes y futuros.

Wittgenstein estaría de acuerdo en que no hay un hecho interno que justifique mi querer decir más o cuás. Lo que va a proponer Kripke, siguiendo un poco las enseñanzas humeanas es lo siguiente: dar una solución escéptica. Así pues, en Wittgenstein on Rules and Private Language, Kripke nos dice: 
En su Enquiry, tras haber desarrollado sus “Dudas escépticas concernientes a las operaciones del entendimiento", Hume da su "solución escéptica a estas dudas". ¿Qué es una solución escéptica? Llamemos solución directa a una solución propuesta para un problema filosófico escéptico en caso de que muestre que, examinado éste más de cerca, el escepticismo resulta injustificado; un argumento esquivo o complejo prueba la tesis de la que dudaba el escéptico. [...] Una solución escéptica de un problema filosófico escéptico comienza, por el contrario, concediendo que las afirmaciones negativas del escéptico son irrebatibles. ${ }^{72}$

Es de suma importancia recalcar que la solución, al ser una solución escéptica, no requiere de una respuesta directa, sino que lo que hay que decir es que debemos concederle al escéptico que sus afirmaciones son irrebatibles.

Veamos, pues, cómo se disuelve el problema. En primer lugar, hay que rechazar las condiciones de verdad, tal como en el Tractatus, es decir, que la explicación general del significado se da por medio de sus condiciones de verdad. La contraparte en el mundo que hace verdadero un enunciado. Son bien conocidas las famosas líneas que expone el primer Wittgenstein las cuales sustentan toda la teoría pictórica del significado. Esto es, a cada proposición le corresponde un hecho posible, si dicho hecho ocurre, la proposición que expresa el hecho es verdadera, en caso contrario es falsa. En cuanto a las oraciones atómicas, la relación entre el hecho y la oración es de correspondencia o isomorfismo. Cada

\footnotetext{
72 "In his Enquiry, after he has developed his 'Sceptical Doubts Concerning the Operations of the Understanding' Hume gives his 'Sceptical Solution of These Doubts'. What is a sceptical solution? Call a proposed solution to a sceptical philosophical problem a straight solution if it shows that on closer examination the scepticism proves to be unwarranted; an elusive or complex argument proves the thesis the sceptic doubted... A sceptical solution of a sceptical philosophical problem begins on the contrary by conceding that the sceptic's negative assertions are unanswerable [...]". (Kripke, 1982: 66)
} 
oración contiene nombres que se corresponden a su vez con objetos. Por lo tanto, podemos decir que cualquier oración declarativa obtiene su significado a través de sus condiciones de verdad, esto es, por la correspondencia que mantiene con el mundo o por los hechos que pudieran darse. Por ejemplo, 'el león está en la jaula' es entendida por aquellos hablantes que la reconocen como verdadera si y sólo si cierto león está en la jaula; es falsa en otro caso. Es decir, la presencia del león en la jaula es un hecho en el mundo que, si se diera, haría verdadera la oración. Es decir, las Investigaciones contienen un rechazo de la idea fregeano-tractariana de que la forma general de explicar el significado es por medio de sus condiciones de verdad. Esto es, se reemplaza la pregunta ¿qué ha de ser el caso para que esta oración sea verdadera? Por otras dos, a saber: ¿En qué condiciones puede esta oración aseverarse o negarse? Y ¿Cuál es la utilidad en nuestras vidas de nuestras prácticas de aseverar o negar tales oraciones? ${ }^{73}$

En segundo lugar, hemos de intercambiar las condiciones de verdad por condiciones de aseverabilidad. Es decir, no se buscan condiciones suficientes y necesarias para seguir una regla, ya que tales condiciones constituirían una solución directa al reto escéptico y ya ha sido rechazada. Lo que debemos dar son las condiciones de aseverabilidad de cómo usamos y justificamos el seguir una regla. No se razonará a priori cuál es el papel que deben jugar tales enunciados.

Ningún hecho se corresponde con enunciados como "Jones quiere decir adición mediante ' + '". Jones quiere decir adición mediante “+" si tiene intención de usar el signo "+" de una cierta manera y quiere decir cuadición si tiene intención de usarlo de otra. Sin

\footnotetext{
73 Trataré el tema más adelante
} 
embargo, es cierto que las intenciones no iluminan lo que Jones quiso decir. Pero ¿no decimos que son verdaderas o falsas dichas aserciones? Podríamos decir "es un hecho que Jones quiere decir adición mediante ' + '” sin embargo, esto no sería más que dar un ejemplo de lo que llamamos la teoría de la redundancia de la verdad. Afirmar que un enunciado es verdadero, o anteponer 'es un hecho que', es simplemente afirmar el enunciado mismo. $(' p$ ' es verdadero $=p)$.

Consideremos, pues, el caso de un individuo tomado de manera aislada, casi todos nosotros cuando se nos pregunta por la suma de 68 y 57 damos la respuesta de 125 . Esto es, no pensamos en posibles hipótesis sobre reglas cuasiformes, ya que como he dicho anteriormente, el reto no es un problema sobre la aritmética, sino sobre la noción del significado en general. Es decir, en constantes ocasiones actuamos sin razón alguna por la cual podamos justificar nuestras acciones, actuamos sin dudar, pero actuamos a ciegas. Es lo que Wittgenstein en ocasiones Ilama hablar sin justificación, pero no ilegítimamente. Parte de nuestro juego del lenguaje es que en ocasiones damos las respuestas sin dar justificación alguna, es decir, actuamos acorde a nuestras inclinaciones. Sin embargo, no debe pensarse que, si ese individuo piensa que sigue de manera correcta la regla, lo esté haciendo. Es por ello que tanto, Kripke como Wittgenstein, reniegan que se pueda seguir una regla de manera privada. ¿Es imposible, por lo tanto, decir que Crusoe no puede seguir reglas si se encuentra aislado? Creo que no se sigue, quizá podríamos pensar que no tiene sentido decirlo. Pero, si pensamos que Crusoe sigue reglas, entonces lo estamos acogiendo como parte de nuestra comunidad y le imponemos nuestros criterios con los que decimos que alguien sigue reglas. Es decir, habría que matizar que podemos decir que un individuo 
físicamente aislado puede seguir reglas, pero un individuo aisladamente considerado (esté aislado físicamente o no) no se puede decir que las siga. Es decir, nuestra comunidad ejerce como tribunal y para ello echa mano de tests para decir si sigue reglas tal como se aplican con el resto de la comunidad. El ataque contra el lenguaje y/o modelo privado debe entenderse como aquel intento de explicar que una persona sigue reglas únicamente desde la perspectiva del mismo seguidor de reglas, sin hacer referencia a la comunidad. Me parece que una idea importante es que el hecho de que la comunidad funja como tribunal, no obliga a abandonar la autoridad que tiene uno sobre sí mismo.

Ampliar nuestros horizontes, dirigir la mirada a la comunidad y no sólo al seguidor de reglas en solitario, ayudará a entender de mejor manera cómo es que decimos que seguimos reglas. Existen otros seguidores de reglas y ellos, a su vez, tendrán condiciones de justificación ${ }^{74}$ y éstas no consistirán sólo en asentir lo que dice el seguidor. Supongamos el caso de niño que está aprendiendo a sumar, nos resulta evidente que su profesor no pensará que cualquier respuesta que dé el niño es correcta, sólo porque el niño dice estar en lo correcto. El niño debe mostrar con suficiencia que domina la adición y, para ello, debe dar respuestas correctas, primero para cálculos los pequeños, para después seguir con algunos de mayor complejidad. Cuando el niño se equivoca debe ser posible reconocer que está intentando seguir el proceso que le fue enseñado y no un proceso cuasiforme. El

\footnotetext{
${ }^{74}$ Pensemos en las condiciones de justificación como aquellas donde el seguidor de reglas sigue sus propias inclinaciones, es decir, Wittgenstein piensa que usar una palabra sin justificación no quiere decir utilzarla ilegítimamente. (Autoridad de la primera persona)Así nos dice, Kripke, (Nota 63) Cuando utilizamos 'condiciones de justificación' hemos de construirla de modo que incluyan tales casos donde Wittgenstein diría que no hay justificación. Por lo tanto, 'condiciones de aseverabilidad' debe ser entendida desde la perspectiva de tercera persona, donde hay una comunidad que puede refrendar nuestros usos.
} 
método de juzgar del profesor debe regirse por lo que él mismo daría como respuesta, es decir, el procedimiento debe ser el mismo por el que el profesor se inclinaría.

Por lo tanto, ahora podemos identificar condiciones de aseverabilidad aproximadas para enunciados del tipo "Jones quiere decir adición mediante 'más'" si Jones posee confianza en su modo de proceder, es decir, tiene la inclinación a seguir de modo correcto y está sujeto a corrección por parte de los demás. Kripke piensa que las inclinaciones tanto la general; ahora sé cómo seguir, como las particulares, dando respuestas especificas a determinados cálculos han de considerarse como primitivas. Esto es, aquellas no requieren de justificación para las habilidades de Jones. Sin embargo, no ha de entenderse que Smith deba aceptar la autoridad de Jones al respecto sin chistar, es decir, Smith aceptará que Jones quiere decir adición mediante 'más' sólo si sus respuestas concuerdan en suficientes casos para mostrar que, de hecho, siguen el mismo procedimiento. Las respuestas estrafalarias o insensatas serán tomados como que Jones no sigue la misma regla en absoluto. De ningún modo ha de pensarse que Jones y Smith si concuerdan en sus respuestas tienen la misma regla en su mente, pues como hemos visto no hay hechos sobre lo que uno quiere decir con sus palabras. Si las respuestas entre Jones, Smith y los observadores externos discordarán todas entre sí, ésta práctica no tendría ningún interés. Sería una especie de parloteo sin ton ni son. Sin embargo, en la vida diaria nos percatamos de que los usos con respecto a la adición suelen ser bastante uniformes y es por ello que si un individuo alcanza la suficiencia de casos atinados, puede con razón llamársele un sumador. Lo que a la postre se le admitirá como un hablante normal del lenguaje y se le incluirá en la comunidad. Aún así, hay casos donde los hablantes divergen de tal modo en 
sus respuestas que no pueden ser admitidos dentro de una comunidad ni de sus interacciones diarias. Otro punto que cabe destacar es que las condiciones de aseverabilidad permiten explicar el error, en particular cómo explicaríamos los errores de cálculo. Recuérdese que el problema del error es una fuerte objeción al disposicionalismo.

Regresemos al punto, ¿cuál es la utilidad de las prácticas antes descritas? Regularmente asumimos que las interacciones con la gente se dan sobre la base de que la gente entiende, por ejemplo, el concepto de adición, del mismo modo que lo haríamos nosotros. Recuérdese la situación del tendero y las manzanas en las Investigaciones. Es decir, esperamos que el tendero no calcule de manera errónea, que no dé respuestas estrafalarias. Es cierto que puede cometer errores, incluso intentar hacer cálculos fraudulentos, sin embargo, si el cliente espera que el tendero tenga el dominio del concepto de adición, en ocasiones dará el mismo resultado que hubiera pensado él mismo. Un juego del lenguaje consiste precisamente en esas interacciones y en atribuir posesión y dominio de conceptos a los demás esperando que ellos se comporten como nosotros.

Debemos, pues, mirar y no pensar cómo se usan tales afirmaciones. En todo caso el uso correcto o incorrecto de reglas es una cuestión que debe ser evaluable por una comunidad de hablantes competentes. Decimos que alguien sigue cierta regla cuando sus respuestas concuerdan con las nuestras y discordan cuando no. Dos personas que hacen cálculos de adición pueden tener desacuerdos y pensar que alguno de ellos no ha captado la regla. Pero dichas discordancias serían por meros errores de cálculo. En nuestra comunidad los usos de la adición son bastante uniformes. Alguien que sostenga que ha captado la regla debe, por lo tanto, ser capaz de responder adecuadamente a los casos 
simples $(1+1,3+3,7+7,9+9 \ldots)$. Sin embargo, no es imposible pensar que dos personas concuerdan en sus respuestas, pero en realidad siguen reglas distintas, ¿ pero qué problema habría con ello? Existen dos individuos, A y B, ellos deben continuar la serie $2,4,6,8,10 \ldots$ como es de esperarse ambos, también el lector, puede desarrollar la serie sin mayor problema. Sin embargo, sabemos que cualquier persona con una mínima instrucción matemática sabe que la serie puede continuarse de indefinidas maneras distintas, usando reglas distintas que arrojen el mismo resultado, a saber, 12 . No creo que haya problema con ello, quizá se podría objetar que la concordancia aquí sólo se da a un nivel superficial, mera coincidencia, pero ¿no estamos siempre en este nivel? Es decir, lo que podemos ver son conductas/respuestas observables y no podemos ver dentro de la mente.

Tenemos pues el siguiente condicional: si Jones quiere decir adición mediante "+", entonces si se le pregunta por "68 + 57", él dirá "125". Sin embargo, dicho condicional parece decir que a partir de un estado mental en Jones se puede garantizar su éxito en las adiciones particulares, pero esto es justamente lo que niega el reto escéptico. De nuevo, no hay hechos que justifiquen lo que queremos decir con nuestras palabras o, mejor dicho, que nos den la pauta de cómo debemos actuar en un futuro.

Recordemos que un condicional es equivalente a su contrapuesto, por lo cual, Wittgenstein echará mano de este recurso para dar cuenta de las condiciones de justificación para este tipo de enunciados. Tenemos el siguiente contrapuesto: Si Jones no responde " 125 " cuando se le pregunta por "68 + 57", entonces no podemos aseverar que quiere decir adición mediante “+". Por supuesto, el antecedente debería incluir algunas cláusulas de más. Es decir, habría que aclarar que Jones podría haberse equivocado al hacer 
el cálculo, podría estar distraído, etc. y por ello no responder "125". Sin embargo, si acogemos a Jones como parte de nuestra comunidad, le estamos imponiendo nuestros criterios de seguir una regla. Por lo tanto, si le adscribimos a Jones la posesión del concepto de adición, entonces esperamos de él que no exhiba una conducta estraflaria siguiendo reglas cuasiformes. Es decir, esperaríamos que las respuestas tuvieran un grado de concordancia suficiente para mostrar que ha entendido la adición. Wittgenstein, así como Kripke, asumen que atribuir conceptos a individuos es un juego del lenguaje. No atribuimos algún estado mental, lo que hacemos es darles cabida en la comunidad, mientras su conducta divergente no los aparte de la misma. Sin embargo, en la práctica, dicha conducta divergente y/o estrafalaria extrañamente ocurre. La solución escéptica nos permite hacer, por lo menos, dos cosas de suma importancia: proporciona las condiciones de justificación para poder atribuir conceptos y, a su vez, explica cuál es la utilidad de este juego en nuestras vidas.

Tres conceptos suelen ser la base de la explicación. En primer lugar, tenemos la concordancia. El juego de atribuir posesión de conceptos de forma justificada radica en mostrar conformidad suficiente con la conducta, donde en situaciones de prueba el individuo muestre que puede satisfacer los criterios que sigue y dicta la comunidad misma. Por ejemplo, si ante la petición de calcular "68 + 57", una persona respondiera "125", otra " 5 " y otra "89" el juego de atribuir conceptos a individuos ni siquiera vendría a cuento. Es decir, no podría existir. Pero, como sabemos, la concordancia ocurre y extrañamente hay conductas desviadas. Los errores ciertamente ocurren, pero surgen porque son muestra de un adiestramiento insuficiente y/o de una mala comprensión. 
En segundo lugar, tenemos lo que Wittgenstein llama formas de vida. Es decir, para éste nuestras interacciones diarias, la manera en que concordamos y el modo en que dichas actividades se entretejen son formas de vida. Es decir, seres que siguen reglas cuasiformes y que concuerdan en sus respuestas compartirían otra forma de vida, sin embargo, para nosotros sería una forma de vida estrafalaria y no podríamos entenderla. No debe malinterpretarse que todos respondemos a "68 +57 " como lo hacemos porque todos captamos el concepto de adición de la misma manera, i.e., no es por un hecho objetivo que queremos decir adición mediante “+”, más bien, nuestra autorización para afirmar que queremos decir adición mediante el signo “+” se debe a un juego del lenguaje simplemente por el hecho de que concordamos. Por supuesto, nada garantiza que la captación y atribución de conceptos no fallará mañana. Es decir, nos inclinamos a la Hume, a confiar en la regularidad y no en argumentos a priori. Es decir, dicha regularidad ha de aceptarse como lo dado, como las formas de vida.

En tercer lugar, examinemos la noción de criterios. Hemos dicho que la solución escéptica depende de la concordancia y de la comprobabilidad, esto es, las habilidades de las personas para saber si usan las palabras del mismo modo en que nosotros lo haríamos. Decimos que un niño ha adquirido el dominio de la palabra 'mesa' si y sólo si el niño dice la palabra cuando ve un objeto al que los adultos llaman por 'mesa'. Es decir, el niño basado en su observación y en concordancia con el uso de los adultos profiere la palabra 'mesa' en circunstancias similares y confirman la preferencia del niño. Sin embargo, ¿cómo se da la concordancia para términos como 'dolor'? Sabemos que el niño ha captado de manera correcta la palabra 'dolor' sólo si la profiere cuando siente dolor y no en otro caso. Es decir, 
un adulto podría refrendar que utiliza de manera adecuada el término, si la conducta y las circunstancias externas indican que tiene dolor. Es decir, si el niño lo hace bajo dichas condiciones y no lo hace en otro caso, diríamos, como adultos, que el niño ha adquirido la noción de dolor. Al parecer lo que intenta decir Wittgenstein es que los procesos internos están influenciados por los criterios externos que nos son observables, éstos serían, principalmente, la conducta del niño. El ejemplo antes mencionado de la mesa podría pensarse como un paradigma entre objeto y designación. Resulta tentador pensar que si ese es el caso general de designación, entonces debería poder ser aplicable a las demás palabras, por ejemplo, 'dolor'. Es decir, podría sugerirse que la palabra 'dolor' no puede ser confirmada por un adulto como en el caso de 'mesa'. La sugerencia de Wittgenstein es que no hay paradigma a priori que dicte cómo deben aplicarse las palabras, pues no hay alguno que rija nuestras formas de vida. La concordancia, como he dicho, es la que nos permite atribuir conceptos.

Resumamos, la solución escéptica puede echar luz sobre el reto escéptico si se abandona el intento de encontrar un hecho alguno en cuya virtud se quiere decir algo y ese mismo hecho deba decirme cómo continuar en el futuro. En su lugar, hay que ver cómo son utilizadas, en primer lugar, (i) la aserción categorial; de que un individuo esté siguiendo una regla dada. Y, en segundo, lugar, (ii) la aserción condicional de que si un individuo sigue tal y cual regla, entonces debería actuar de tal y cual modo en una ocasión determinada. En tercer lugar, (iii) en el caso de individuos aislados, podemos decir que es frecuente reconocer que en tales circunstancias el individuo tiene la experiencia de sentir que ha captado la regla y a menudo siente la confianza de saber cómo debería actuar en casos 
futuros, sin embargo, es todo lo que se podría decir, no se podría hablar de corrección e incorreción. Recuérdese que la solución depende de condiciones de aseverabilidad. En cuarto lugar, (iv) si consideramos al individuo dentro de una comunidad, entonces el panorama resulta mejor. Es decir, cuando los individuos de una comunidad aceptan condicionales del tipo (ii), entonces también aceptarían su contrapuesto, i.e., si un individuo no da las respuestas particulares que la comunidad consideraría correctas, la comunidad supondría que no está siguiendo la regla. De manera contraria, si un individuo pasa con suficiencia las pruebas, entonces la comunidad asevera la afirmación (i). Esto es, se le acepta como un seguidor de reglas y apto para participar en ciertos tipos de interacciones.

Podemos decir como corolario que la respuesta correcta al problema de adición (y al problema de querer decir, significar, algo) no es la que todo el mundo da al problema de adición, sino más bien el hecho bruto de que si bien todo el mundo concuerda en una cierta respuesta, nadie estaría tentado a llamarla errónea.

Por último, creo importante recalcar que la solución depende de la idea de que cuando uno sigue una regla (afirma estar siguiendo una regla), puede y debe ser objeto de comprobación por los demás. En este caso el grupo de observadores determinan si su seguimiento de una regla concuerda con lo que ellos harían y refrendar que lo hizo correcta o incorrectamente. La solución depende, entre muchas cosas más, de la concordancia y la comprobabilidad. 


\section{Conclusiones}

En el capítulo 1, titulado Wittgenstein vs Tractatus Logico Philosophicus, se examinaron las críticas que surgieron a partir de las Investigaciones Filosóficas, tratando nociones centrales del periodo del Tractatus, es decir, haciendo un breve recuento de las nociones principales del primer periodo del filósofo vienés. Entre ellas se encuentran nombres, objetos, definiciones ostensivas, siempre a la luz de las críticas vertidas en las Investigaciones. Considero que la noción de seguir una regla se encuentra presente en ambas etapas de Wittgenstein. Es decir, hay reglas de cómo aprendemos nombres, palabras por medio de definiciones ostensivas, etc. A lo largo de este primer apartado me pareció importante mostrar las diferencias que alberga lo que se ha denominado el primer y el segundo Wittgenstein. El objetivo principal de este capítulo fue mostrar grosso modo el cambio de perspectiva entre la explicación del significado por medio de condiciones de verdad correspondientes al primer periodo y la explicación por medio de condiciones de aseverabilidad que le atañen al segundo.

El segundo capítulo, Antirrealismo: Kripke y el argumento escéptico sobre el seguir una regla, intenta defender la conclusión a la que pretendo llegar con esta tesis. La conclusión de que no hay hecho alguno que justifique mi querer decir algo mediante un signo. Es decir, el análisis kripkeano reniega de que la comprensión sea una cuestión privada —que, desde mi punto de vista, Wittgenstein también defiende-. Si suponemos que la comprensión lingüística es un estado mental al cual accedemos de manera privada, 
entonces la relación normativa entre uso de expresiones del lenguaje y comprensión se pierde, ya que como dice la paradoja wittgensteiniana: "una regla no podía determinar ningún curso de acción porque todo curso de acción puede hacerse concordar con la regla... Lo que intento mostrar es que, si concedemos que la comprensión es un estado mental privado, entonces no habría diferencia entre seguir una regla y creer que se sigue la regla; por lo tanto, podríamos argumentar, a modo de conclusión, que la comprensión lingüística no puede ser/fundarse en estados mentales privados. Del mismo modo, creo que Wittgenstein echa mano, así como Kripke, de una perspectiva de tercera persona que permite preservar la noción normativa en cuanto al problema de seguir una regla. Así, llego a la conclusión de que la comprensión no es un estado mental privado y que las nociones de corrección e incorreción toman su sentido a través de una comunidad lingüística que funge como tribunal. Es decir, una perspectiva de tercera persona, me parece tener mayor plausibilidad para dar cuenta de los usos uniformes de las expresiones lingüísticas.

El objetivo del tercer capítulo, Comprensión lingüística y realismo. McGinn: críticas a la paradoja escéptica y solución comunitarista, ha sido, en primer lugar, defender que hay hechos que justifican lo que queremos decir mediante nuestras palabras, es decir, McGinn en su libro Wittgenstein on Meaning. An Interpretation and Evaluation defiende una postura realista con respecto a la comprensión lingüística. Una de sus primeras objeciones apunta a que Kripke malinterpreta en general a Wittgenstein; por ejemplo, McGinn piensa que la paradoja no es como lo hace ver Kripke, la parte más importante de las Investigaciones, sino que en realidad es un reductio que Wittgenstein utiliza para mostrar que hay un modo de seguir una regla que no es una interpretación. 
Una de las principales objeciones de McGinn es que Kripke pasa por alto la teoría causal de la referencia para salir del atolladero donde nos ha dejado la paradoja. Es decir, recordemos que McGinn sugiere que echando mano de dicha teoría es posible hallar el hecho constitutivo que permite resolver la paradoja. Sin embargo, McGinn ofrece una explicación de por qué Kripke evade su propia teoría. En primer lugar, la paradoja tal cual se presenta se da en términos del significado y no de referencia, ya que si la hubiera pensado en términos de referencia su propia teoría hubiera desvanecido su paradoja. $\mathrm{Y}$, en segundo lugar, Kripke evade su teoría, ya que se ocupa de ejemplificar la paradoja con ejemplos matemáticos donde la noción de referencia es claramente problemática.

En particular, no creo que McGinn esté en lo correcto. Kripke no formula su paradoja en términos de referencia porque basta con mencionar que ésta aplica para cualquier tipo de palabra del lenguaje y no da evidencia contundente para mostrar que la referencia es normativa. Del mismo modo, considero que no hace falta examinar la segunda objeción de McGinn que considera que se basa sólo en ejemplos matemáticos. Pues aclarando que la paradoja aplica para cualquier palabra o término, se sigue que también incluye los ejemplos matemáticos.

Recordemos que McGinn objeta que es necesario extender la paradoja a nivel del pensamiento, i.e., actitudes proposicionales, con el fin de que la paradoja sea robusta y no pueda ser disuelta como lo he mencionado. No obstante, a favor de Kripke podríamos decir lo siguiente: es cierto que McGinn puede tener atisbos de razón en cuanto a que la paradoja debe ser extendida. Mas pienso yo que Kripke no menciona las actitudes proposicionales 
porque la paradoja, en primer lugar, parte de la noción naive ${ }^{75}$ de lo que queremos decir mediante un signo y, en segundo lugar, nos conduciría a aceptar una ontología polémica sobre las actitudes proposicionales y la noción de pensamiento en general. ${ }^{76}$

Una tercera objeción de McGinn es que considera que la noción de 'capacidad' es lo suficientemente sólida para responder a la paradoja. Esto es, la capacidad de la adición es distinta al concepto de la capacidad de la cuadición y, por lo tanto, nos dice que el contenido del pensamiento al utilizar una u otra función es distinto. Sugiero que Kripke diría algo más o menos como lo siguiente: supongamos que hay distinción de contenido entre la función de la adición y la de la cuadición, aun así no sabríamos si seguimos una u otra función. Es decir, al no haber una perspectiva de tercera persona, no podríamos distinguir entre dichas funciones y, por lo tanto, el carácter objetivo se tambalea. La solución desde la perspectiva de primera persona, como hemos visto, no da buenos resultados.

Por útimo, creo que la paradoja de Kripke es un parteaguas en algunas áreas importantes de la filosofía, en particular, a la filosofía del lenguaje, de la mente. La paradoja es un problema robusto, serio y complejo que ha de tenerse en cuenta como un problema filosófico interesante en sí mismo. Que sea una buena o mala exposición de Wittgenstein es otra cosa.

\footnotetext{
${ }^{75}$ Es decir, la noción pre-teórica de que lo que queremos decir con nuestras palabras dentro cierto discurso tiene un carácter objetivo.

${ }^{76}$ Veáse Jerry Fodor, en particular The Language of Thought (1975).
} 


\section{Bibliografía}

Black, Max (1992), A Companion to Wittgenstein's "Tractatus", Ithaca, N.Y., Cornell University Press.

Boghossian, Paul (1989), "The Rule-Following Considerations", en Mind, New Series, vol. 98, no. 392 (Oct.), pp. 507-549.

Burgos, Rafael (1968), "Sobre el Concepto de 'Objeto' en el Tractatus", en Crítica: Revista Hispanoamericana de Filosofía, vol. 2, no. 6 (Sep.), México, Instituto de Investigaciones Filosóficas-Universidad Nacional Autónoma de México.

Field, Hartry (1980), Science Without Numbers, Oxford, Blackwell.

Fogelin, Robert J. (1987), Wittgenstein. The Arguments of the Philosophers, Londres, Routledge.

Goodman, Nelson (1979), Fact, Fiction, Forecast, Cambridge, MA, Harvard University Press.

Grayling, A.C. (1996), Wittgenstein. A Very Short Introduction, Oxford, Oxford University Press.

Grice, H.P. (1957), "Meaning”, en The Philosophical Review, vol. 66. no. 3, pp. 377-388.

Kenny, Anthony (2006), Wittgenstein, Blackwell Publishing.

Kripke, Saul (1982), Wittgenstein on Rules and Private Language. An elementary exposition. Cambridge MA, Harvard University Press.

Kusch, Martin (2006), A Sceptical Guide to Meaning and Rules: Defending Kripke's Wittgenstein, Chesham, Acumen.

Mc Guinness, Brian (1991), Wittgenstein: El Joven Ludwig (1889-1921), Madrid, Alianza Editorial.

McGinn, Colin (1984), Wittgenstein on Meaning, Oxford, Basil Blackwell.

Monk, Ray (1990), "Ludwig Wittgenstein" The Duty of Genius, Nueva York, The Free Press.

Mota Pinto, Silvio Jose (2009), Escepticismo del Significado y Teoría de Conceptos, México, Anthropos/Universidad Autónoma Metropolitana-Iztapalapa.

Platón (2008), "Teeteto", en Diálogos V, Madrid, Editorial Gredos. 
Soames, Scott (2009), "Skepticism about meaning: Indeterminacy, Normativity and the Rule Following Paradox", en Philosophical Essays, vol. 2: The Philosophical Significance of Language, Princeton University Press, pp. 385-415.

Stenius, Erik (1960), "Wittgenstein's Tractatus" A Critical Exposition of its Main Lines of Thought, Oxford, Basil Blackwell.

Wittgenstein, Ludwig (2009), Tractatus Logico-Philosophicus, Nueva York, Cosimo.

Wittgenstein, Ludwig (2004), Investigaciones Filosóficas, Barcelona, UNAM/Crítica.

Wittgenstein, Ludwig (2002), Tractatus Logico-Philosophicus, Madrid, Alianza Universidad.

Wittgenstein, Ludwig (2002a), Diario Filosófico (1914-1916), Madrid, Editorial Síntesis.

Wittgenstein, Ludwig (1985), Philosophical Investigations, Oxford, Basil Blackwell.

Wittgenstein, Ludwig (1974), Remarks on the Foundations of Mathematics, Oxford, Blackwell.

Wittgenstein, Ludwig (1961), Tractatus Logico-Philosophicus, Nueva York, Humanity Press.

Wright, G.H. von (1963), Norm and Acgtion: A Logical Enquiry, Londres, Routledge and Kegan Paul. 